\title{
CSAE WPS/2008-16
}

\author{
Votes and Violence: \\ Evidence from a Field Experiment in Nigeria*
}

\author{
Paul Collier ${ }^{\dagger}$ and Pedro C. Vicente
}

First Draft: December, 2007; This Version: June, 2008

\begin{abstract}
:
Following the wave of democratization during the 1990s, elections are now common in low-income societies. However, these elections are frequently flawed. We investigate the Nigerian general election of 2007, which is to date the largest election held in Africa and one seriously marred by violence. We designed and conducted a nationwide field experiment based on randomized anti-violence grassroots campaigning. We find direct effects on violence outcomes from exploring both subject-surveying and independent data sources. Crucially, we establish that voter intimidation is effective in reducing voter turnout, and that the violence was systematically dissociated from incumbents. We suggest that incumbents have a comparative advantage in alternative strategies, vote buying and ballot fraud. Voter intimidation may be a strategy of the weak analogous to terrorism.
\end{abstract}

JEL Codes: D72, D74, O55, P16.

Keywords: Violence, Conflict, Electoral Politics, Political Economy, Randomized Experiment, Field Experiment, Nigeria, West Africa

\footnotetext{
* We wish to thank Robert Bates, Cátia Batista, Tim Besley, Michael Bratton, Marcel Fafchamps, Yvan Guichaoua, Abdul Mustapha, Luís Santos-Pinto, and Laura Valderrama for helpful suggestions. We are particularly grateful to Ojobo Atukulu, Otive Igbuzor, and Olutayo Olujide at ActionAid International Nigeria, Austin Emeanua, campaigners Nwakaudu Chijoke Mark, Gbolahan Olubowale, George-Hill Anthony, Monday Itoghor, Umar Farouk, Emmanuel Nehemiah, Henry Mang and their field teams, and to the surveyors headed by Taofeeq Akinremi, Gbenga Adewunmi, Oluwasegun Olaniyan, and Moses Olusola: their professionalism, courage, and dedication to this project were truly outstanding. We also want to acknowledge the kind institutional collaboration of the Afrobarometer. We thank seminar participants at LSE-Oxford IIG-RPC Workshops, Oxford, Navarra, World Bank, CSAE Conference, Edinburgh, NovaLisbon, Gothenburg, CERDI, NCDE-Stockholm for useful comments. We wish to acknowledge financial support from the DfID - Department for International Development (UK), in the context of the "Improving Institutions for Pro-Poor Growth' RPC. All errors are our responsibility.

Department of Economics/CSAE - University of Oxford. Email: paul.collier@economics.ox.ac.uk.

¥ Department of Economics/CSAE - University of Oxford, and Bureau for Research and Economic Analysis of Development - BREAD. Email: pedro.vicente@economics.ox.ac.uk.
} 
"This election is a do-or-die affair."

- President Olusegun Obasanjo, February 10 2007

\section{Introduction}

The slow growth of Africa over the period since independence is now understood as being partly attributable to poor governance. Until the 1990s the predominant African political system was autocracy. As Besley and Kudamatsu (2007) show, while in some contexts autocracy has produced good economic performance, in Africa it has consistently been dysfunctional. During the 1990s many African autocracies were replaced by democracy, most dramatically in the region's largest society, Nigeria. Given the dismal record of autocracy, there was a reasonable expectation that democracy would achieve both accountability and legitimacy, and thereby both improve economic performance and reduce proneness to political violence. However, the record of elections in Africa and other recent low-income democracies is not encouraging. Kudamatsu (2006) measures government performance by infant mortality and shows that, in Africa, elections produce no improvement except in the rare instances in which the incumbent is defeated. Collier and Rohner (2008) find that, below per capita income of $\$ 2,750$, democracy significantly increases proneness to civil war and various other manifestations of violence, and Collier and Hoeffler (2008) find that in resource-rich economies such as Nigeria, electoral competition worsens economic performance unless combined with strong checks and balances.

We attempt to contribute to a better understanding of the surprising (non-)results of democracy in Africa by focusing on how elections have been conducted. Specifically, politicians may have been heavily reliant upon illegitimate strategies for getting elected. Indeed, numerous recent African elections aroused widespread international accusations that parties/candidates had resorted to miscounting of votes, bribery, and/or intimidation. Although these strategies may be inherently associated to the failure of democracy to improve government performance, our objective is to go well beyond the anecdotal: the comprehension of their specific causes and consequences may open new avenues for development policy intervention.

While we provide evidence on determinants of all three referred strategies, the main contribution of this paper is to use a field experiment to study the use of violence to intimidate voters. The context for our analysis is the 2007 Nigerian full round of national and state-level elections: this proved to be an all-too-suitable context for our purposes, as during the two days of these elections 
over 300 people were killed. To the best of our knowledge this is the first paper formally analyzing electoral violence, and one of the few papers applying experimental methods to the study of elections in the developing world (the others being Wantchekon, 2003, and Vicente, 2007a). We investigate how intimidation changes voter behavior and which candidates are most identified with electoral violence.

To be able to unambiguously identify our causal relationships of interest we need exogenous variation in violence-related variables. To this purpose we designed and conducted a field experiment where a campaign against political violence was randomized across neighborhoods and villages of 6 states of Nigeria (representing all main socio-economic regions of the country). This campaign was conducted in half of those locations before the 2007 round of elections by a major international NGO, ActionAid, specializing on community participatory development. It included town meetings, popular theatres and the distribution of campaign material. It was aimed at empowering citizens to counteract local violence, and its activities were designed to reduce the costs of 'protest' and collective action. It also explicitly appealed to 'voting against violent politicians'.

Our measurement was based on a panel of 1149 survey respondents in all treatment and control areas of the experiment. These subjects were interviewed both before the anti-violence campaign and after the elections, and constituted the primary focus of campaigners. The interviews elicited a wide range of measurements of experience with and perceptions of violence (including specific incentive-compatible measurements). Subjects were also asked to report their intended and actual voting behavior (before and after the elections). Our survey-based violence variables were complemented by the compilation of actual violence measures from event-diaries for each location, kept by independent local journalists. Since there is a possibility of conformity bias from the treatment on subject-perceptions ${ }^{1}$, we drew 300 additional respondents at the post-election stage, in treated areas only, who were not directly approached by the campaign. We also asked about the closest network of each respondent in the full sample. Both additional sets of data allow us to run robustness tests on the validity of subject-reports.

The main mechanism of action we propose in this experiment is therefore based on the effect of the campaign on grassroots' views and perceptions about violence (which ultimately caused less occurrences of violence at the local level). Crucially, the described primary exogenous effect of

\footnotetext{
${ }^{1}$ See Vicente (2007a) for a quantification of this potential bias.
} 
the campaign enables us to answer our main empirical questions: on the effect of violence on voter turnout (by instrumenting violence with the randomized campaign), and on identifying the candidates that are most associated to violent behavior. Additionally, the effectiveness of the NGO campaign in reducing both the perception and the actual level of violence itself has notable policy implications.

Our most important empirical results point to violence as a systematic electoral strategy with systematic consequences for votes. Violent intimidation was identified to reduce voter turnout by a clear $10 \%$ for each $1 / 6$ increase in electoral violence. And it was a strategy predominantly linked to non-incumbent groups (sometimes identified as the main political opposition, as is the case of AC in presidential elections). These results are based on robust effects of the campaign on violence outcomes, both using surveyed-subject reports and journalists' diaries. We also find that, in contrast with electoral violence, vote buying and ballot fraud tend to be associated with the incumbent and with more electorally-contested (swing) areas.

We interpret these results in the context of a specific model of electoral competition. There, both incumbent and challenger may intimidate voters towards abstention. In addition, only the incumbent may bribe voters to vote for him and may use ballot fraud to win the election. The incumbent, who always wins the election in equilibrium, only cares about winning; the Challenger only cares about his share of the popular vote. Swing voters contrast fear with money offered; base voters are assumed to condition their base support to a peaceful campaign by their candidate. In the model, intimidation comes from the Challenger when he is least competitive, while vote buying and fraud arise when the Challenger is most competitive.

In Section 2 we set out a theoretical framework of illegitimate election strategies. Section 3 describes the Nigerian context. Section 4 discusses the design of the experiment, a fuller description together with displays of campaign materials being given in Appendices 1 and 2 . Section 5 gives an overview of the results, using descriptive statistics. Section 6 presents our core econometric results and offers robustness tests. Section 7 concludes with some implications for policy.

\section{How to Win an Election: A Model of Electoral Violence, Vote Buying, and Fraud}


Citizens are generally expected to use their vote or even lobby (Becker, 1983) to further their interests. However, there may be imperfections. Besley (2006) reviews the consequences if voters have poor information about government performance (analyzed in-depth by Grossman and Helpman, 1996, for a prominent example), or if the allegiance of many voters is predetermined by loyalties determined by identity. As information deteriorates and allegiance is frozen, a point is reached beyond which those potential politicians who are ill-motivated are not disciplined by the fear of losing votes and so enter politics. However, in elections analyzed by mainstream political economy the strategies open to candidates remain confined to those prevailing in the mature, high-income democracies: only strategies oriented to please regular citizens are considered. In many of the newly democratic low-income countries the only aspect of democracy that has been introduced is elections. There are neither 'checks-and-balances' upon the use of power, nor effective regulations for the conduct of the election. Indeed, in Nigeria, the introduction of elections in 1999 was preceded by 38 years of the postcolonial era of which 30 were spent under military ruling, and so no such regulations were in place.

In this context we propose an original model where electoral violence, vote buying and fraud are strategies available to politicians to help earning political power in elections. Note that among these strategies vote buying is the only one providing voters with a benefit. Let us describe our interpretation of these strategies in more detail.

The use of violence to intimidate voters may have clear advantages. If targeted on discouraging known opponents (e.g. as when allegiance is determined by identity) from voting, the pertinent voter behavior is highly observable (i.e. the polling station merely needs to be observed). Further, it is likely to be widely available to both incumbent and challenger: one hired gang can constitute a credible risk of violence to many voters. Vote buying suffers from the obvious limitation that if the ballot is secret it is difficult for the politician to enforce the bargain. It may nevertheless become effective either if the secrecy of the election is doubted, or if the voter attaches moral value to keeping her word. If we take vote buying as encompassing clientelism the enforcement problem is solved since 'payments' (e.g. public-sector jobs) will be conditional on being elected. These strategies are likely to advantage the incumbent, who is expected to have more money, may be suspected of being in a position to subvert the secrecy of the ballot, and is likely to be more convincing in proposing to 'clients' (sometimes by using resources from office holding). Finally, vote miscounting is expected to advantage the incumbent since the incumbent is more 
likely to control the vote-counting process (e.g. the electoral commission). These are assumptions we take to our model.

We now present a formal electoral game where an incumbent $I$, a challenger $C$, and a continuum of voters of mass 1 interact to allocate political power. The timeline of the sequential complete information game is illustrated in Figure 1. It is related to Groseclose and Snyder (1996) who explain vote-buying behavior in the context of a sequential game. The Incumbent moves first by setting vote buying (or clientelism). Then, closer to the election, Incumbent and Challenger choose their levels of intimidation. Subsequently, voters decide whether to vote and for whom. Finally, the Incumbent may decide to use fraud to win elections (overriding the popular vote). Note that the asymmetry between Incumbent and Challenger on the range of strategies available (namely on vote buying and ballot fraud) is an assumption of the model, made for simplicity, that is tested in the empirical part of this paper.

\section{Figure 1: The Sequence of the Game}

Game Timeline

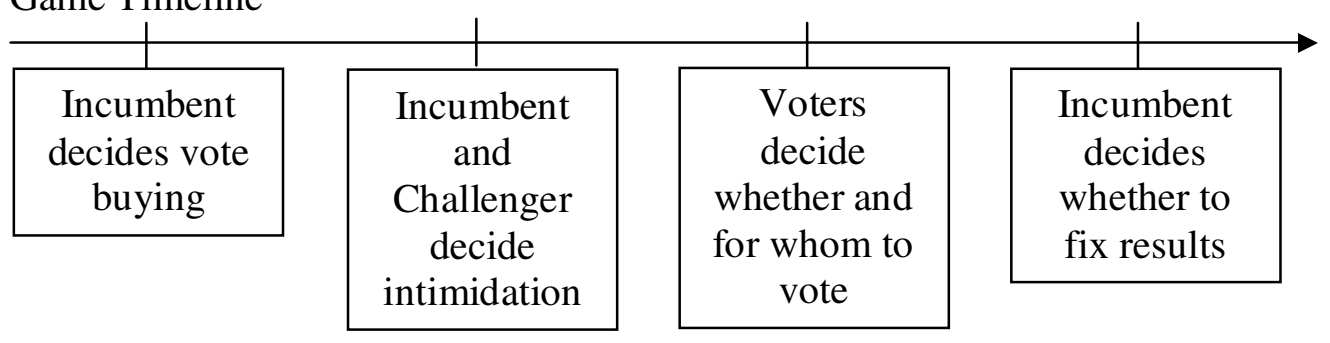

Voters are defined on a continuum, with voter $i \in[0,1]$. For simplicity we assume that each candidate has a base vote of share $b_{j}(j=I, C)$, with $0<\lambda \leq b_{j} \leq 1$ ( $\lambda$ is the minimum base size, close to 0 ). We postulate that neither vote buying nor intimidation can affect base voters' decisions on whether and for whom to vote. The remaining voters are 'swing' and drawn to the polls for private benefits or losses that are enforceable, as described next.

Voter $i$ will vote for the Incumbent if

$$
V B_{i}>I_{i}^{C}+I_{i}^{I}
$$

with abstention chosen if 


$$
V B_{i}<I_{i}^{C}+I_{i}^{I}
$$

For the case of swing-voter indifference,

$$
\text { i.e. } V B_{i}=I_{i}^{C}+I_{i}^{I}
$$

which also constitutes our initial 'swing' status quo, we break the tie by punishing the candidate who has minimal base supporters. In other words, if $b_{C}=\lambda \wedge b_{I}>\lambda$, then indifference is broken in favor of the Incumbent; conversely, if $b_{I}=\lambda \wedge b_{C}>\lambda$, indifferent swing voters side with the Challenger. This assumption is meant to attribute a cost to extremist, 'anti-social' candidates, i.e. those holding the smallest base-voter share $\lambda$ : when one such candidate is present, any swing voter at indifference is biased towards supporting the mainstream, alternative candidate. For symmetry, abstention is the decision taken by swing voters at indifference in case both candidates either have higher than minimal or minimal base supporters.

We need to make a further hypothesis regarding intimidation. Although intimidation may help the candidates by reducing the turnout of supporters of their respective contenders, we assume that it comes at a cost. As the intimidating candidate becomes identified with violence his committed, above-minimal base supporters are lost to the 'swing' mass, i.e. his support base is reduced, if larger, to $\lambda$ which may be thought of as extremist support. Regarding base voters, we therefore assume an endemic distaste for violence.

We now turn to the payoffs of the candidates. We postulate there are two prizes to fight for: the executive prize, attributed to the candidate who wins the election (fixed), and a second-tier, political influence prize, which is allocated to the loser - this is measured by the share of the votes of the loser in the election (variable). This is because the loser is able to extract rents proportionately to his electoral performance ${ }^{2}$. The candidates face the payoff

\footnotetext{
${ }^{2}$ This assumption could be interpreted in the context of a three-candidate game, where a third political player (a bureaucracy) would be inactive and entitled to obtain the second-tier residual power share, i.e. the Incumbent's share of voting. Still, we would be implicitly assuming the winning candidate does not care about second-tier political influence - a simplification in our game.
} 


$$
P_{j}-C_{j}
$$

for $j=I, C$. Political benefits $P$ are defined as

$$
P_{j} \equiv a W_{j}+b S_{j}
$$

There, $W_{j}=1$ in case $j$ is the winner of the election - $W_{j}=0$ otherwise. $j$ may win the election either through fraud (but only if $j$ is the Incumbent) or, in its absence, through a majority at the ballot, i.e. a share of the votes of $50 \%+\varepsilon$ or higher. $S_{j}$ is defined as the actual (ballot) voting share of candidate $j$ if $j$ is the loser of the election - $S_{j}=0$ otherwise. We assume that winning the election is more attractive than all losing outcomes $(a>b)$, and that both winning the election and earning votes as the loser confer large benefits relative to costs ( $a, b$ sufficiently high). Costs are defined as

$$
C_{I} \equiv \int_{0}^{1}\left(V B_{i}+I_{i}^{I}\right) d i+F \text { and } C_{C} \equiv \int_{0}^{1} I_{i}^{C} d i
$$

where $V B$ is vote buying, $I$ is intimidation, and $F$ is the cost of fraud ( $F=1$ if the Incumbent uses fraud or $F=0$ otherwise). We assume that the Incumbent has sufficient resources for ballot fraud always to be feasible, i.e. $C_{I} \leq 1$ (where 1 is total resources available to the Incumbent), and that the Challenger is constrained by $C_{C} \leq M_{C}$ (where $M_{C}>0$ stands for total resources available to the Challenger).

\subsection{Equilibrium}

We now solve the game for the unique sub-game perfect equilibrium, by analyzing the different parameter sets (i.e. values of $b_{I}, b_{C}, M_{C}$ ).

First, given the assumptions on the size of the budget of the Incumbent vs. the cost of ballot fraud, we know the Incumbent will, if necessary, always resort to fraud to win the election. 
Hence, in equilibrium, given the assumptions on $a$ and $b$ the Incumbent always wins the election and the Challenger always maximizes his share of votes as the loser.

We begin by considering the case where $b_{I}>b_{C}$ and $b_{C}=\lambda$, i.e. where the Challenger is an extremist and the Incumbent has larger base support. As a dominant strategy, the Incumbent will want to spend nothing on vote buying, intimidation or fraud - he is already guaranteed to win the election $\left(b_{I}>b_{C}\right)$. Given this behavior, the Challenger will want swing voters to abstain rather than side with the Incumbent which they are inclined to do due to the Challenger's extremist position. By threatening intimidation the Challenger can achieve a discrete jump in his share of vote at negligible cost. We therefore observe intimidation from the Challenger (only) but neither vote buying nor fraud, the case being depicted in Figure 2.

Figure 2: Pure Intimidation

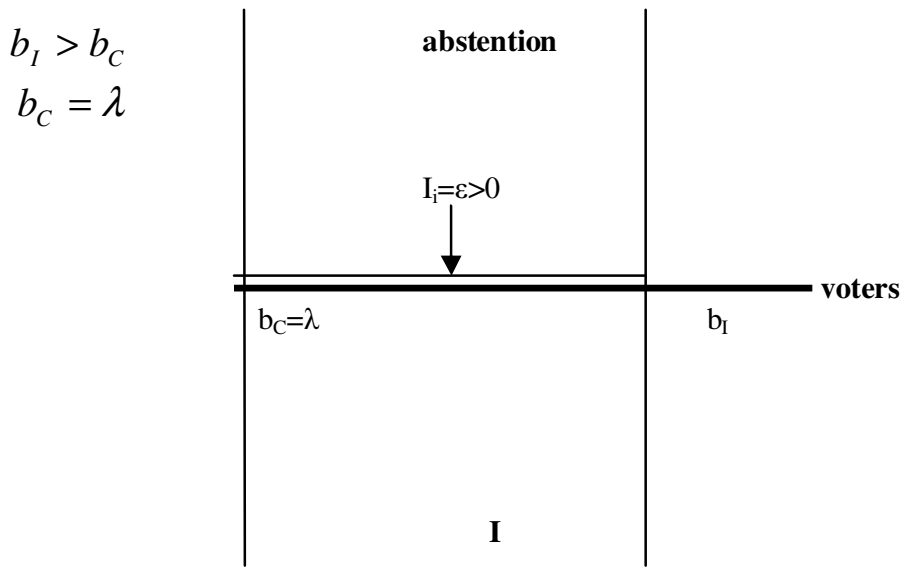

Now consider the situation in which $b_{I}>b_{C}$ and $b_{C}>\lambda$. In this parameter set it is still a dominant strategy for the Incumbent to be passive. Now however, were the Challenger to resort to intimidation, he would lose his base and so necessarily see his vote share decreased. This is the case of conventional politics: none of the illegitimate strategies - intimidation, vote buying and fraud - is used.

We now turn to cases where the Challenger's base is sufficiently large to pose a threat to the Incumbent's objective of winning the election $\left(b_{I} \leq b_{C}\right)$. 
We begin by considering $b_{I}>\lambda$ and $b_{C}<0.5$. Since $b_{I}>\lambda$, swing voters abstain and there is no point in the Incumbent using intimidation (a strictly dominated strategy). Since a Challenger who resorted to intimidation would lose his above-minimal base and thereby receive a smaller share of votes, he fights a clean campaign. However, were the Incumbent to fight a clean campaign he would lose the election and so he has to choose among the remaining illegitimate strategies. We find the Incumbent resorts to vote-buying, purchasing just enough votes to take a majority $\left(b_{C}+\varepsilon\right)-$ that will be cost-effective (relative to fraud) given negligible vote-buying spending. In this setting, we therefore see vote buying but neither intimidation nor fraud (see Figure 3$)$. Note that $b_{C}<0.5$ guarantees that the Incumbent may buy a majority.

\section{Figure 3: Pure Vote-Buying I}

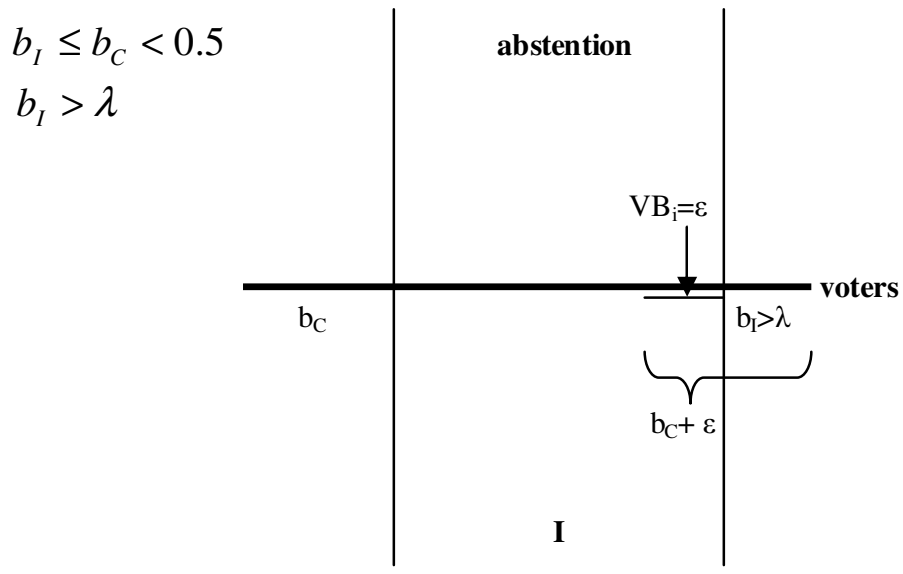

If $b_{I}=\lambda$, the Incumbent is still obliged to choose at least one of the illegitimate strategies to win the election. We may have two outcomes depending upon the size of the Challenger's base (relative to majority) and the size of the Challenger's budget (relative to the Incumbent's), with the latter determining the relative attractiveness of vote buying and fraud for the Incumbent.

First suppose that $b_{C}<0.5$ and $M_{C}<1$. As before, $b_{C}<0.5$ opens the possibility that the Incumbent buys a majority in equilibrium. Moreover, we know that for the Incumbent to win the election through the popular vote, he will have to induce some additional voters to vote for him: he cannot just rely upon intimidation. Suppose the Incumbent buys $b_{C}+\varepsilon$ voters, paying just enough to get them to vote, with the remaining swing voters intimidated towards abstention or 
(indifferently for the Incumbent) bought. Then the best response by the Challenger would be to intimidate all non-base voters on the Incumbent's side towards abstention, yielding an electoral victory for the Challenger at negligible cost. The Incumbent must therefore lead the Challenger to consider spending his entire budget on intimidation - i.e. a race to the bottom. Since the Incumbent wants to win the election, he will buy the share of voters $0.5-b_{I}+\varepsilon$ ( $\varepsilon$ in case $\left.b_{I}=b_{C}=\lambda\right)-$ otherwise the Challenger would remain passive (non-violent) and win the election. The Incumbent will race to the bottom by spending $M_{C}+\varepsilon$ with the referred voters (in any way - see Figure $4, V B^{*}$, for an example), so that the Challenger will not be able to bring back all of them towards abstention. Crucially this amount is feasible under the condition $M_{C}<1$, and in fact makes vote buying preferable to fraud (cost-minimizing). Note that, for the Incumbent, spending resources with intimidation (on any voter) is useless, as it does not oblige the Challenger to match these expenses when he responds. The Challenger will therefore be indifferent in terms of electoral results between intimidating and not intimidating. Hence, he will opt for the cheapest: clean campaigning. In this parameter set we therefore see only vote buying emerging in equilibrium - neither intimidation nor ballot fraud arise.

\section{Figure 4: Pure Vote-Buying II}

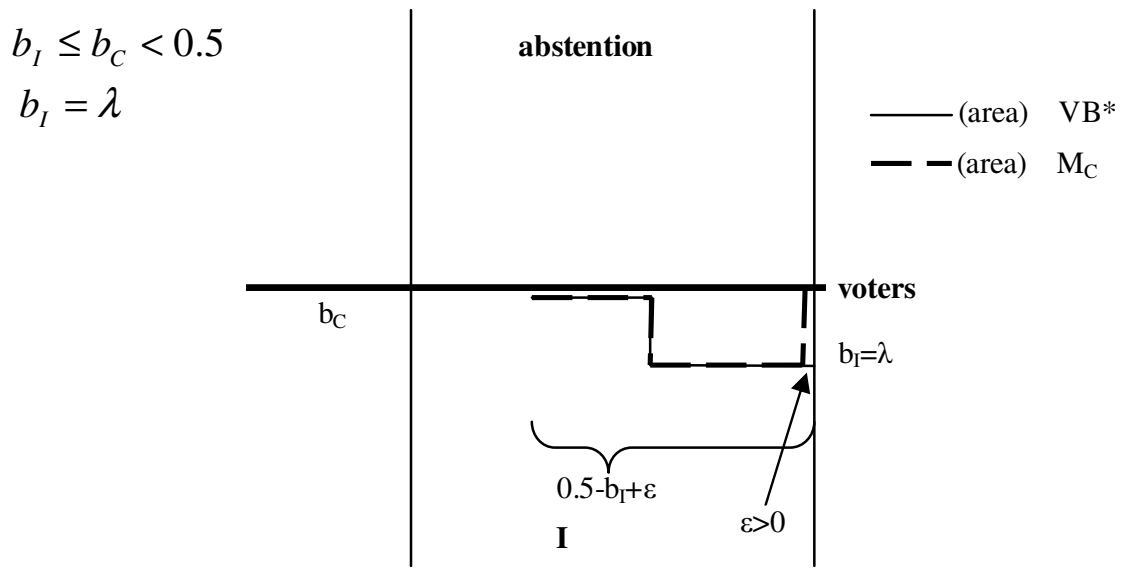

Now suppose instead that either $b_{C} \geq 0.5$ or both $b_{C}<0.5$ and the maximum vote buying that the Incumbent can afford is weakly lower than what the Challenger can intimidate back (i.e. $M_{C} \geq 1$ ). If $b_{C} \geq 0.5$, clean campaigning is a dominant strategy for the Challenger. For $b_{C}<0.5$ and $M_{C} \geq 1$, the Incumbent has insufficient resources to win a potential race to the 
bottom. Both possibilities mean the Incumbent cannot use vote buying to win the election, and so must resort to fraud. In this parameter set we therefore see only ballot fraud arising in equilibrium.

The model thus predicts that in situations where the Challenger is strong no violence will arise. In these cases the Incumbent will win the election by resorting to either vote buying or fraud. In contrast, when the Incumbent has sufficient support to win through an honest campaign, the Challenger may resort to violent intimidation, but he will do so only if he runs on marginal electoral support. In this model, the Incumbent never uses intimidation in equilibrium.

\section{Background: The 2007 Nigerian Election}

Nigeria is the most populous country in Africa, with estimated 135 million inhabitants in $2007^{3}$. Despite being a major oil producer, with the $10^{\text {th }}$ largest oil proved reserves in the world $(35 \mathrm{~b}$ barrels) ${ }^{4}$, it ranks 201 in 233 countries in terms of GDP per capita (1400 USD PPP in $2005^{5}$ ). As implied by this failure to harness oil revenues for growth ${ }^{6}$, the quality of governance has been low: in Transparency International's Corruption Perception Index it ranks 147 in 179 countries $(2007)^{7}$. In Chinua Achebe's (1983) words, 'the trouble with Nigeria is simply and squarely a failure of leadership'.

From 1999, with the passing of a new federal constitution, Nigeria moved to civilian rule ${ }^{8}$, under democratic elections: these happened in 1999, 2003, and 2007. However, all of these elections were damaged by widespread electoral malfeasance. By many accounts these elections were far from being 'free and fair'.

The election of 2007, which is the focus of our study, covered four distinct contests: presidential; federal house of representatives and senate; gubernatorial; and state assembly. Under Nigeria's federal constitution power is particularly concentrated in the president and the state governors.

\footnotetext{
${ }^{3}$ CIA World Factbook.

${ }^{4}$ Oil \& Gas Journal, 103(47), December $19^{\text {th }}, 2005$.

${ }^{5}$ World Development Indicators.

6 In this view, we believe the analysis of the Nigerian case also contributes to a better understanding of political incentives in resource-rich countries - and therefore of the 'natural resource curse' (Sachs and Warner, 1995; Mehlum et al , 2006; Robinson et al, 2006; Vicente, 2006, 2007b; Collier and Goderis, 2007).

${ }^{7}$ See Smith (2007), for a thorough account of the phenomenon of corruption in Nigeria.

${ }^{8}$ See Maier (2000) for a description of this transfer of power and recent political history of Nigeria.
} 
The 2007 election was not contested by the incumbent president, Obasanjo, due to his term limit. The key contestants were Umaru Yar'Adua, Muhammadu Buhari, and Atiku Abubakar. Yar'Adua was Obasanjo's chosen successor in the ruling PDP (People's Democracy Party). However, he was little known since until June 2006 Obasanjo had been hoping to change the constitution to permit a third term. Buhari had already been the main challenger in the 2003 election, and was standing for the ANPP (All Nigeria Peoples Party). A previous military ruler, his regime had been noted for a public campaign against corruption. Abubakar, although the incumbent Vice-President, was in serious conflict with President Obasanjo, and had been forced to switch party to the AC (Action Congress). Previously a customs officer with controversial sources of wealth, he had been indicted by the federal anti-corruption commission EFCC on multiple charges related with campaign fund embezzlement and bribery. At the core of the election campaign was the manifest determination of President Obasanjo to prevent VicePresident Abubakar from becoming the next president. In a phrase that became famous, Obasanjo described the election as a 'do-or-die affair'.

The ruling PDP duly won the election with $70 \%$ of votes, as did 28 of its candidates in the 36 gubernatorial elections. However, the election was deeply flawed through violence, bribery and vote miscounting. As illustration we present the assessments of three well-informed independent organizations:

'Rigging, violence and intimidation were so pervasive and on such naked display that they made a mockery of the electoral process. [...] Where voting did take place, many voters stayed away from the polls. [...] By the time voting ended, the body count had surpassed 300.' - Human Rights Watch.

'The irregularities were so numerous and so far-reaching that the election was a charade and did not meet the standards required for democratic elections.' Transition Monitoring Group (an NGO with 50,000 Nigerian observers).

'Nigeria's elections were not credible and fell far short of basic international standards. [...] Elections for president, state governors and legislators were marred by violence, poor organisation, lack of transparency, significant evidence of fraud, voter disenfranchisement and bias.' European Union Electoral Observation Mission. 
These unfortunate features make the election well-suited for a study of electoral violence. In particular, violence may not have been simply a random spill-over from heightened antagonisms: it might have been used systematically as an electoral strategy.

\section{The Design of the Experiment}

To identify effects of violence on voting we need exogenous variation. Since the distribution of violence cannot be assumed to be random, our research design was centered around introducing a randomly distributed reduction in the perceived threat of violence and measure the consequences of this reduction. While to our knowledge this is the first application of experimental methods to the study of electoral violence, the method has already been demonstrated to be effective in other electoral contexts. Wantchekon (2003) pioneered the application to African elections, evaluating randomized political campaigns in Benin. He showed that for the incumbent a message of patronage to favored groups was more effective than one of national public goods. Vicente (2007a) comes closest to the current paper, analyzing an information campaign against vote buying practices ${ }^{9}$. Experimental methods have also been applied to more conventional election techniques (in American elections) such as canvassing, phone calls, and direct mail (Gerber and Green, 2000; Gerber, 2004).

Evidently, the most difficult part of our research design was to achieve a significant reduction in the perceived threat of violence in selected locations. As we will show, our intervention to reduce the perceived threat of violence was successful. However, necessarily our intervention could not eliminate the perceived threat: hence, our results provide merely a lower bound estimate of the full effects of voter intimidation on voter behavior.

We allied with the Nigerian chapter of a large and effective NGO, ActionAid, which regarded the prospect of political violence as a grave challenge to democracy and wished to counter it. ActionAid's input on designing a powerful campaign against political violence draw on its specialist expertise in community participatory development and its experienced field infrastructure. Its campaign included town meetings, street theatre, and the distribution of campaign materials all highly concentrated in particular locations. We provide details of the campaign in Appendix 1.

\footnotetext{
${ }^{9}$ In related empirical work, though non-experimental, Brusco et al (2004) use survey methods to analyze vote buying in Argentina.
} 
The campaign was designed to oppose voter intimidation through two distinct routes. The first was to neutralize intimidation by lowering the perceived threat to individual voters. The analytic foundation for this aspect of the campaign is the model of political protest of Kuran $(1989,1991)$. As exemplified by McMillan and Zoido (2004), a public call to a common protest action lowers its costs and so makes it easier to resist intimidation ${ }^{10}$. More specifically, if politician A threatens the known supporters of B, then the more B supporters who turn up to vote the lower the risk to each of them. At a minimum A's capacity for violence is spread over a larger group of potential victims, and quite possibly beyond some point the perpetrators of violence are themselves intimidated into inaction. The turnout of support for B will thus depend upon the expectation of each B supporter as to whether other supporters will ignore the threat. The opposition to intimidation consequently embeds a classic collective action problem. The key test of whether this first route was effective is thus whether it neutralized the turnout-reducing effect of intimidation among supporters of non-violent candidates. The second route by which the campaign aimed to oppose intimidation was to emphasize its lack of legitimacy. This was designed to make people who had intended to vote for those politicians who resorted to violence question whether their support was appropriate. In fact a key component of the slogan of the campaign was 'Vote against violent politicians'. We shall then see whether the campaign could persuade these supporters to switch their vote from violent candidates.

ActionAid agreed to implement the campaign in randomized locations. Given the exogeneity of this treatment, our impact measurement depended on two sources of information: first we conducted a panel survey of 1149 respondents in 24 enumeration areas, with rounds prior to and after the election; second we contracted independent journalists (one per enumeration area) to report/describe violent events that affected the neighborhood or village, through consultation of local bodies (e.g. town meetings, police) - 131 events were identified for the 24 locations, in the period before and after AAIN's campaign ( $2^{\text {nd }}$ semester 2006 to 2 weeks after the last April elections).

The baseline survey was conducted just before the campaign. The households in the survey were then targeted by the campaign in its wide range of door-to-door activities. The post-intervention

\footnotetext{
${ }^{10}$ This idea also relates with theory of informational cascades by Bikhchandani et al $(1992,1998)$ and Lohmann $(1994,2000)$, which was proposed to explain the behavior of the masses.
} 
survey was carried out after the elections, when results were known and post-election stability was achieved.

The survey was representative at the state level, being conducted in two states from each of the three large Nigerian regions (Southwest, Southeast, and North). See Appendix 1 for the details of our sampling framework. The campaign against violence was conducted in half of the enumeration areas, leaving the others as controls. Respondents were asked about violence, about their intended voting behavior, and about their actual voting behavior. Evidently, since our aim was to determine whether the reduction in perceived violence affected voter behavior, the design of the experiment depended upon two stages: that the campaign would reduce the perceived threat of violence, and that this would in turn affect voting. Hence, the surveys were designed to elicit evidence on each stage. The questions on violence were asked both prior to the campaign, focusing on a reference period ('the last year'), and after the campaign/elections, focusing on what had happened just before and during the elections (i.e. 'from January', when the baseline survey was in the field). The questions on voting were based on intentions (before) and selfreported actual decisions (after) regarding all the elections at stake in April 2007. See Appendix 1 for additional details of survey questionnaire design. In the figure below, we show the sequence of the experiment.

Figure 5: The Time Frame of the Experiment

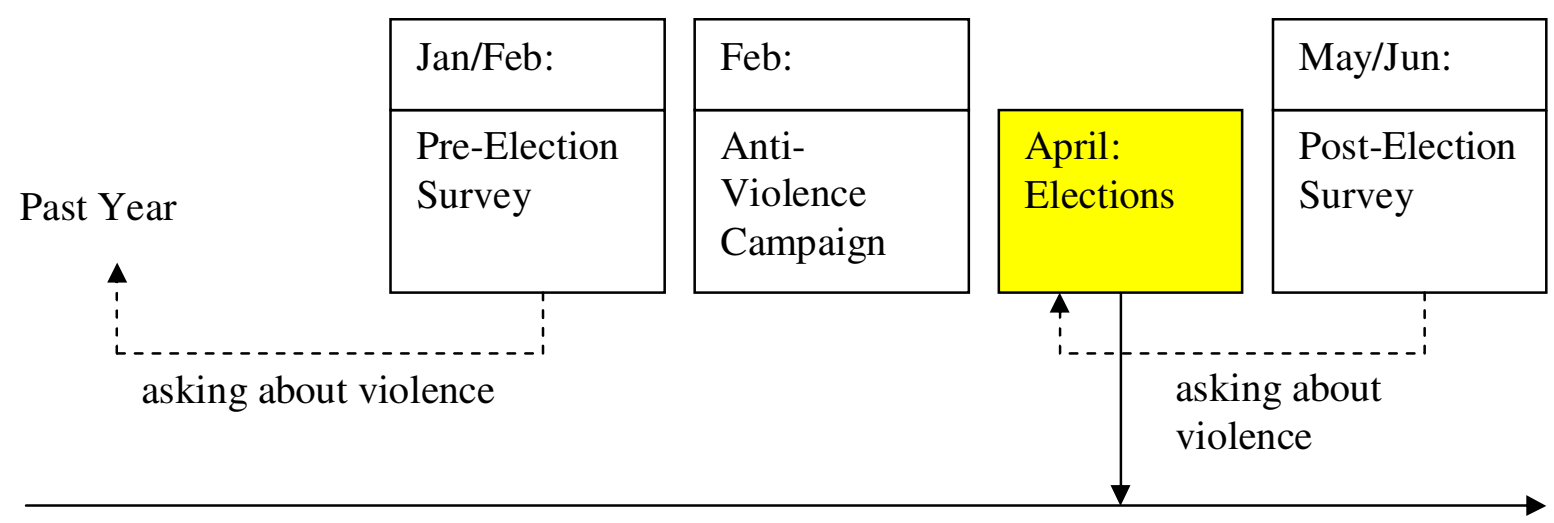

Time Line

This design allows the use of a classic difference-in-differences econometric approach. In a first stage we investigate the effect of the anti-violence campaign on violence outcomes. In addition to 
being of interest in its own right, this is a direct test of the mechanism by which the campaign might have changed voter behavior. The effect can be elicited through the specification:

$$
V C_{i l t}=a+b X_{i t}+c Y_{l}+d t+e T_{l}+f t * T_{l}+\varepsilon_{i l t},
$$

where $V C$ is a violence or crime-related outcome, $i, l, t$ are identifiers for individuals, locations, and time (before/after), $T$ is a binary variable with value 1 for treated locations, $X$ is a vector of controls (demographic, attitudinal), potentially time-varying, $Y$ is a geographical fixed effect.

We can then run a reduced-form specification, yielding the effect of the treatment on voting behavior outcomes:

$$
V_{i l t}=g+h X_{i t}+j Y_{l}+k t+m T_{l}+n t * T_{l}+\varepsilon_{i l t},
$$

where $V$ denotes a voting behavior measure (intended-before and actual reported-after).

We also display results for the estimation of

$$
\Delta V_{i l}=o+p X_{i}+q Y_{l}+r V C_{l}+\varepsilon_{i l},
$$

where violence/crime is instrumented by the treatment variable (provided the identification of significant effects of the campaign in diminishing violence, i.e. from specification 1). This is the way by which we hope to be able to identify the effect of violence on voter turnout.

We use a rich set of individual control variables, including differences in information about candidates before and after the elections, campaign activism, and policy platforms perceived for the candidates and supported by respondents.

Finally, although we do not rely exclusively on survey respondents (also factual data from independent journalists) in our data design, survey measurement may generally have some limitations. In particular, since it is based on subject-reports, there is a possibility of encountering 'conformity biases': subjects may adapt their responses as to 'conform' to 'expected' effects of the treatment. To an extent we are defended from survey conformity biases because the survey 
and the campaign were independent from each other, with distinct field teams and branding. Nevertheless, we attempt to verify the extent of this problem in three ways.

First we created an incentive-compatible individual measure of empowerment to counteract violence: we proposed an observable costly action against violence to all respondents in the survey (see the next section for details). Second, we compare panel respondents, all of whom had been directly approached by the campaign, with an oversample of 300 respondents in treated enumeration areas who were not directly approached by the campaign. We are thus able to contrast those respondents who were subject to the full range of interactions with the experiment (baseline interview, direct individualized campaign, post-intervention interview) with those who only face a post-intervention interview. Crucially, we ask common-knowledge questions, about their 'neighborhood or village'. If conformity bias is serious it should therefore be manifest in a difference between the responses of these two groups. Third, we identify the most closely connected respondents for each respondent in the panel survey. This information is used to correlate voting behavior within networks, and to employ these correlated measures of voting behavior instead of individual self-reports. This exercise allows us to control for measurement biases in voting behavior ${ }^{11}$ that are present across networks.

\section{Descriptive Statistics}

We begin with an overview of how respondents perceived problems with the electoral process in each of the six states (Chart 1). We use a standardized subjective rating system, scaled 1-4 with higher scores indicating a more severe problem. All three of the illegitimate forms of voter influence were of concern to voters. In most states ballot fraud was perceived as the most serious problem, with the question being posed as 'How free and fair are the elections in terms of the 'counting of votes?'. Voter intimidation was usually the intermediate problem, the question being put forward specifically as a concern about 'security against violence originated by politicians'. Vote buying was rated as the least severe problem, although still prevalent, the question being

\footnotetext{
${ }^{11}$ On electoral behavior, we have to date been unable to gather fully disaggregated official electoral results and it seems unlikely that they exist for all locations. Results were announced in terms of the overall totals in a process that appears to have by-passed the need to aggregate actual votes. Note nevertheless that Vicente (2007a) was able to contrast self reports to disaggregated electoral results in Sao Tome and Principe's 2006 presidential election, without significant differences encountered. Although different, Nigeria and Sao Tome and Principe are neighbouring countries, which gives us some assurance that self reports may be an adequate source of voting data in that broader geographical region.
} 
presented in terms of 'someone from a political party offering something, like food or a gift, in return for votes'.

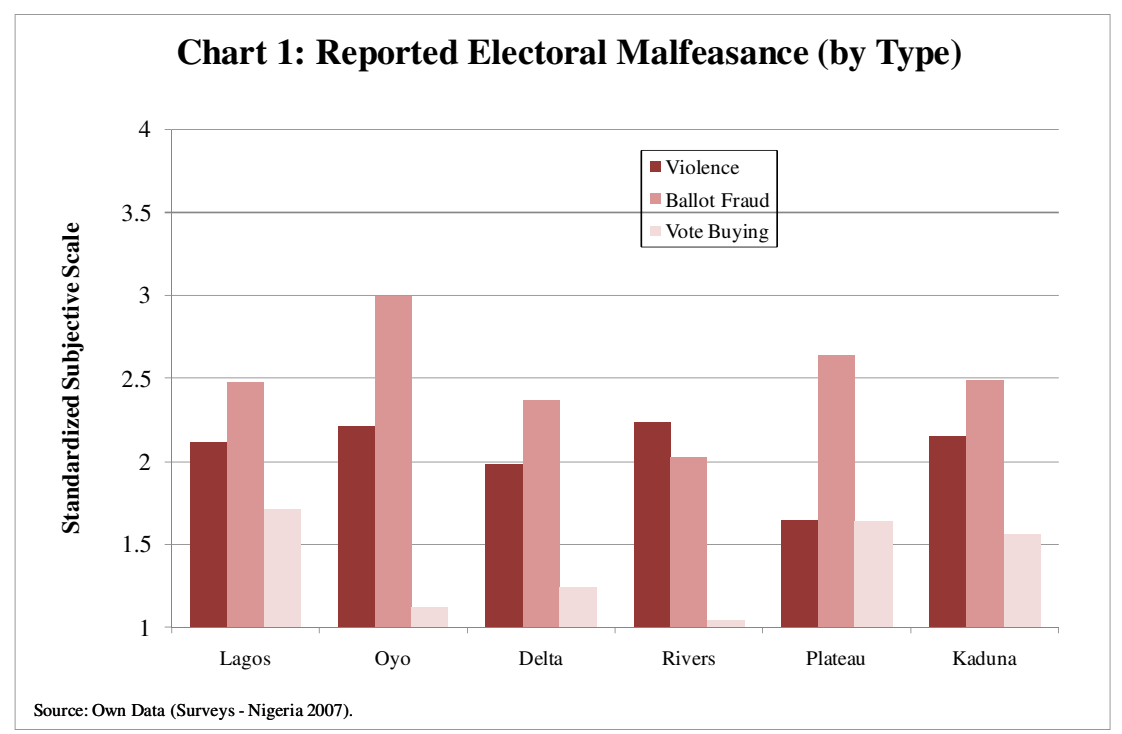

Evidently our approach depends upon the effectiveness of the anti-violence campaign. While we investigate this more formally in the next section, here we provide an overview. Respondents in the panel were asked the same questions twice, once referring to the period prior to the campaign and then referring to the period after it. Respondents in both the treatment and control areas might change their answers due to experiences during the intervening period, but only in the treated areas would respondents have encountered the campaign. We therefore focus on whether the change in responses differs as between treatment and control areas. First, consider four measures of perceived threats: general violence within the community, gang violence, physical intimidation (as a pure crime measure), and violence intensity (classified from journalists diary-descriptions into a 1-5 scale). For all four measures the treatment areas have a larger reduction in perceived threat than the control areas. Further, the two types of perceived violence most pertinent for voter intimidation, gangs and physical intimidation, show large falls in the treatment areas but are virtually unchanged in the control areas. Next, consider the obverse of perceived threats: three measures of confidence in electoral security. Respondents were asked about security, empowerment, and knowledge of how to resist violence. All three measures show larger improvements for the treatment areas than the controls, and again the most pertinent measure, security, shows a large improvement for the treatment areas but virtually no change for the controls. 
Since talk is cheap, as referred, we supplemented the survey with a direct measure of an incentive-compatible action. All respondents were given a postcard which they could choose whether to post. On the card there was a message demanding that more attention be paid to countering voter intimidation. Since in order to post the card the respondent had to go to a postoffice, this was a costly action. The respondent was more likely to incur this cost the stronger was her sense that intimidation should/could be countered - see Appendix 1 for the full description of this variable's design. Thus, differences in the response rate between treated and control areas are a useful measure of whether the campaign was effective. As shown in Chart 2, in both areas response rates were remarkably high: around a third of respondents returned the card, this being consistent with a high degree of concern about the problem. But response rates were even higher in treated areas than in their controls.

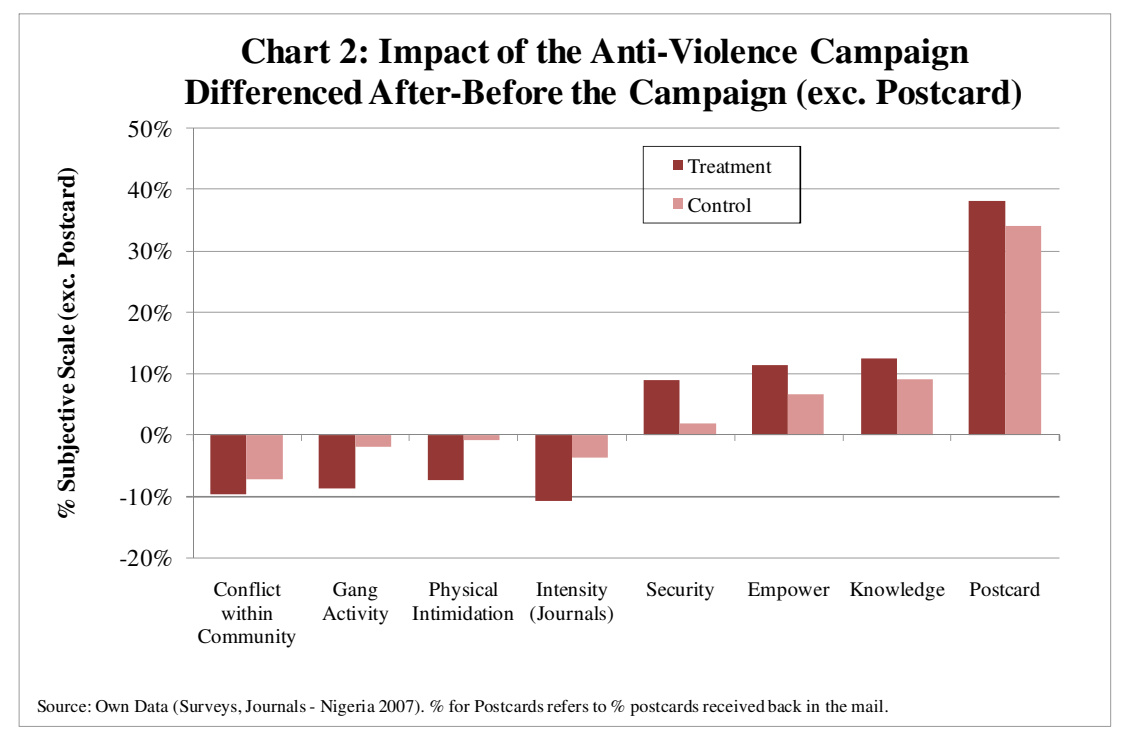

Since there is some basis for regarding the campaign as effective, the consequential question arises as to whether the perceived reduction in the threat of violence in the treated areas actually changed voting behavior. Again, the two-round structure of the survey is helpful in that it enables us to focus directly on the change between stated intentions during the first round and actual voting behavior as reported during the second round (see Chart 3).

First, consider voter turnout. Unsurprisingly, in both treated and control areas the election campaign succeeded in mobilizing people to vote: many people who in the first round of the survey had stated that they did not intend to vote ended up voting. In the treatment areas this 
effect was clearly larger. The difference is consistent with the hypothesis that citizens who had been intimidated into deciding not to vote found the 'courage' to do so as a result of a perceived reduction in threat generated by the campaign. However, we are particularly concerned to see whether voter intimidation was used strategically by politicians. Hence, we are interested in the effect of the anti-violence campaign on the supporters of each party/candidate individually. There is a clear pattern. The incumbent parties, both at the presidential and gubernatorial levels, mainly PDP, clearly gained as a result of the campaign. Supporters who had intended not to vote appear to have been empowered by the campaign to turn out and vote for incumbents. However, the campaign had an objective beyond its core intent to empower people to resist being intimidated into not voting. The appeal to 'vote against violent politicians' aimed to weaken support for candidates who supported violence. Respondents initially intending to vote for a politician perceived as violent may have decided either to abstain or even to switch to other candidates. Most clearly at the presidential level, AC lost support. This is consistent with instability being a strategy of political desperation: Abubakar, the leader of the AC, had neither the advantages of the incumbent PDP, nor of the ANPP as the northern established opposition party.

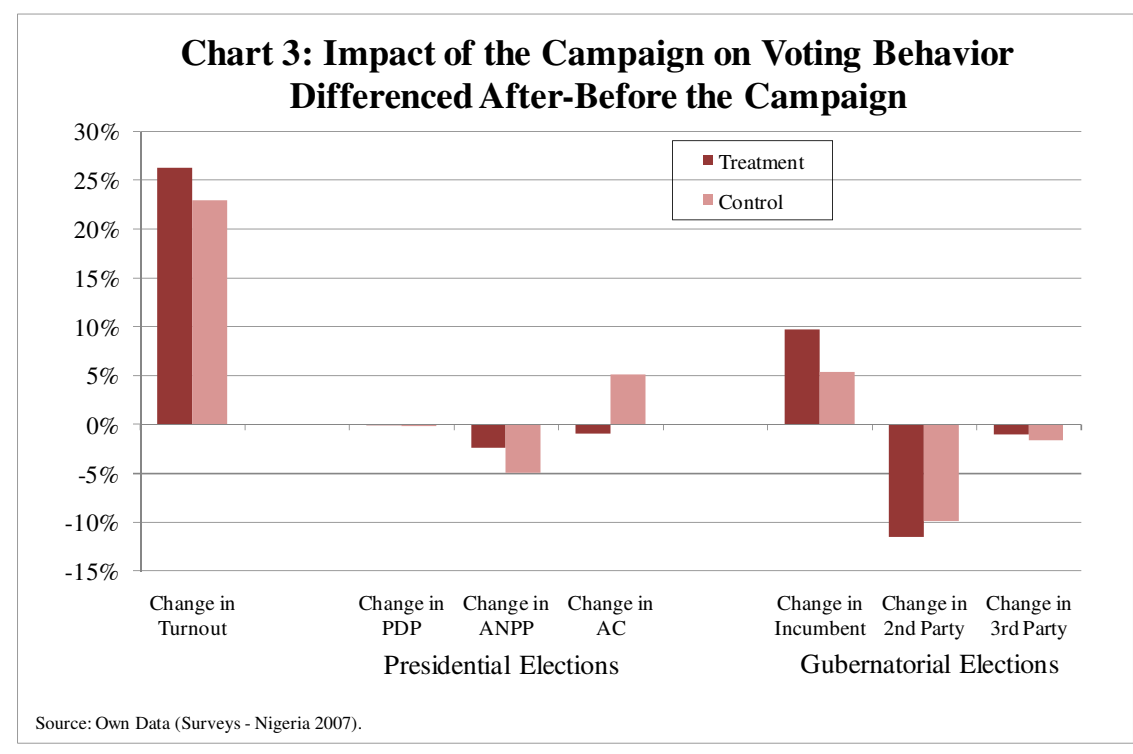

Indeed, for both the presidential and gubernatorial elections, we find evidence consistent with both objectives of the campaign. PDP supporters were more likely to switch from an intention not to vote to actually voting in treatment areas. In contrast, AC supporters who had initially intended to vote were more likely to abstain in treatment areas, and this abstention effect was reinforced by 
vote switching: AC supporters were also more likely to switch to the PDP in treatment locations. We revisit this decomposition in the next section.

\section{Econometric Results}

We begin by exploring whether the three illegitimate electoral methods, violence, vote buying, and ballot fraud, are allocated systematically. These results do not use the anti-violence experimental design; they target location-wide determinants of the perceived importance of these methods in the late stages of the 2007 election campaign. The results are presented in Table A1 in Appendix 3. We begin with a simple specification in which the explanatory variables are the expected tightness of the election, and whether the ruling PDP is incumbent in the state. Tightness is proxied by the absolute difference between incumbent and opposition scores at the location level in the previous gubernatorial ${ }^{12}$ elections in 2003 . We also control for whether the enumeration area is urban although in the event this is only significant for violent intimidation. The OLS results find that the tighter is the election the greater are the perceived problems of vote buying and ballot fraud, the two strategies that we have suggested are best-suited to the incumbent. In contrast, violence is significantly reduced if the race is competitive. The effects are large: treating the four-point scale of responses as linear, in tight races vote buying is perceived as being $41 \%$ greater $^{13}$ and electoral fraud $53 \%$ more frequent. In contrast, violence is perceived as being far less of a problem in tight races, with a reduction of $25 \%$. All these effects are statistically significant at the $1 \%$ level while clustering standard errors at the enumeration area level. This is evidence consistent with the idea that political expenditures on vote buying and fraud are used strategically when the election is competitive. In contrast, violence may be an instrument used for making a political stand by weaker parties or groups when they do not hold significant base support (analogously to terrorism). We continue exploring this hypothesis in the remaining of the paper.

Controlling for the tightness of the race, PDP incumbency at the state level increases the perceived problem of ballot fraud (by 15\%), consistent with the hypothesis that for this strategy a combination of national and local incumbency is needed.

\footnotetext{
${ }^{12}$ The use of gubernatorial election scores reinforces the local nature of political competition we want to capture.

${ }^{13}$ The same result appears in Vicente (2007a), consistently with classical swing voter theory (e.g. Dixit and Londregan, 1996), regarding the use of vote buying in Sao Tome and Principe.
} 
We next focus more closely upon the chosen strategies by the PDP. While PDP as the national incumbent evidently had the advantage in terms of ballot fraud, for the other two strategies respondents were asked which party they regarded as the main perpetrator. To investigate the strategic use by the PDP of these other methods we create a variable which measures for each method the prominence of the PDP relative to other parties in these reports. We then weight the incidence of each method by this ratio. With this new dependent variable we find that in locations where the PDP is the incumbent it is less likely to resort to violence but more likely to resort to vote buying. All effects are statistically significant at least at the 5\% level whether we control only for state dummy variables, or include basic infrastructural characteristics of the $\operatorname{sites}^{14}$ and individual demographic and attitudinal controls ${ }^{15}$.

We also present a very similar exercise using the nationally-representative, 37-state sample of the 2007 pre-election Afrobarometer survey. While the main dependent variables are the same, the subjacent questions were asked in the pre-election period. We find a very similar pattern, which allows us to state that our experimental sites do not differ much in terms of electoral strategies from a nationally-representative sample.

The core of our analysis is on the effects of electoral violence on voting and on identifying 'violent politicians', and for these we need to rely upon the anti-violence campaign. This requires two preliminary steps: the demonstration that the treatment is indeed randomized, and the demonstration that the campaign was effective in changing the perceived threat of political violence.

In Appendix, Tables A2, we compare the characteristics of the treated and control groups: their demographic profiles, baseline violence outcomes, and baseline self-reported electoral preferences. Since these variables are unaffected by the intervention, any differences between treatment and control are a product of luck. We generally find no statistically-relevant differences (at standard levels) between treatment and control groups. The exception is that the control group

\footnotetext{
${ }^{14}$ These were chosen from a list of variables concerning the enumeration areas: existence of post office, school, police station, electricity grid, piped water, sewage system, health clinic, recreational facilities, places of worship, town halls or community buildings, market stalls.

${ }^{15}$ Demographic controls are chosen from a wide range of variables: gender, age, household head and size, marital status, ethnic group and language, religion (faith, intensity), schooling, job status, occupation, property, household expenditure and welfare, health status. Attitudinal controls include: consistency measures, interest in public affairs, media exposure, campaign activism, knowledge about candidacies, policy (perceptions about candidates, own preferences).
} 
seems to have better knowledge of ways to counteract violence (+9\%). This is therefore evidence that the randomization was generally effective in gathering comparable groups of locations and respondents.

Table A3 in Appendix reports our regressions testing whether the campaign was effective on changing violence-related measures. We use a wide range of perception and experience variables from our survey measurement. The first set concerns general political freedoms: on 'thinking', on 'joining a party', on 'voting freely', on 'being free from insecurity', and on the perceived fairness of elections, in general and as related to violence. We then focus on general perceptions at the local level: conflict ('within the local community' contrasted to 'within family'), intimidation ('threatening negative consequences in order to induce voting in a certain way'), and electoral violence ('general violence related to politics'). We distinguish between violence from the top and empowerment against/sympathy for violence at the bottom. For the first set of variables, we display perceptions concerning 'influence of political assassinations on instilling a climate of fear' (frequent in the 2006 primaries), politicians 'openly advocating violence', 'violent gangs being active', and 'security from violence originated by politicians'. For the second set, we analyze 'support for do-or-die affair', 'local population's standing against violence originated by politicians', 'empowerment' and 'knowledge of ways to resist violence', as well as the postcard variable, and sympathy for violence. The final set of survey violence measurements comes from a batch of standard questions (both perceptions and experience) on local crime (which could be indirectly related to politics - namely through gang activities): 'thefts in public places', 'purposely-made damages to property (vandalism)', 'physical threats/intimidation', and policeinduced problems.

We use specifications with classical difference-in-differences (regressions on the levels specification 1 above). Where level-measurement is not available, namely for questions asked only in the post-election survey, we rely upon time differences (gathered from the post-election survey) regressed on treatment. The first specification for each outcome variable is run with state dummy variables to control for geographical fixed effects, while the second adds controls for individual demographic and attitudinal characteristics. We use OLS regressions for all outcomes ${ }^{16}$

\footnotetext{
${ }^{16}$ Although these outcomes are based on subjective scales, provided the way these scales were handled during the fieldwork (described in the Appendix 1), we are secure that assuming linear distances between the different levels is appropriate. As a robustness test, we did run Ordered Probit regressions - these generally showed no relevant difference to OLS estimates.
} 
except for the postcard variable, where we use Probit. We cluster standard errors at the level of the enumeration area.

Overall we found clear effects of the campaign in most violence-related measures, the results being robust both in terms of magnitude and statistical significance to the inclusion of individual controls. The campaign changed responses on political freedoms by $9-12 \%$, and those on free and fair elections by $18-21 \%$. In terms of general electoral violence at the local level we found: for 'conflict within the local community' there was a $12 \%$ effect; in contrast, there was no significant effect on perceived conflict within families, which was, of course, not an objective of the campaign; we observe a $5 \%$ change in intimidation directly conditional on voting.

On local violence originated at the top, effects ranged from a $6 \%$ change in the influence of assassinations, an $8 \%$ change in politicians advocating violence and in gang activity, to a $10 \%$ change in security from violence originated by politicians.

On empowerment against/support for violence at the local level, we find very clear effects: $12 \%$ on support for 'do-or-die' at the grassroots, $8 \%$ on knowledge of ways to counteract violence. Recall that in addition to these perceptions the research design included an incentive-compatible action: whether the respondent went to the post office to send an anti-violence postcard. We thus also analyze effects of the campaign on the postcard variable, a measure that we interpret as empowerment to counteract violence. Treated respondents were found to send the postcard $14 \%$ more frequently than their control counterparts, with statistical significance at the $10 \%$ level.

We now turn to our survey measures of crime in the locality. The campaign was designed primarily to increase people's willingness to withstand intimidation, rather than actually to reduce related forms of criminality. We generally find no significant effects on experience with crime but significant effects on perceptions of crime in its different forms ${ }^{17}$.

In Table A4 (Appendix), we show effects of the treatment on intensity of electoral violence, as reported by independent local journalists (based on information gathered from direct observation

\footnotetext{
${ }^{17}$ We did however find a clear 5\% decrease on perceptions of police-induced problems as a result of the campaign, i.e. in the same direction as most other violence outcomes. This finding reassures us that the campaign does not seem to have been understood by respondents as biased in favor of the incumbent (who controls the police), as one would expect from the independent nature of the campaign sponsor (international NGO ActionAid).
} 
and local institutions like police and town meetings). We find a $13 \%$ reduction in the intensity of electoral violence, significant at the $10 \%$ level. Once we add incidence to our main regression, we keep the same sign but lose the statistical significance. The clear effect on incidence constitutes evidence that there was an effect on perpetration of (actual) violence. Indeed, the induced reduction in the effectiveness of intimidation (the direct aim of the campaign) could lead to a reduction in the actual level of electoral violence as politicians adjusted their strategies. In the event, although we find that the campaign generally did not have significant effects on actual (experienced) general crime, we find some evidence that actual electoral violence diminished in intensity. This fact helps us to interpret our survey-based results away from pure conformity-like effects.

We now turn to the effects of our randomized campaign on the electoral behavior of our panel of respondents. Tables A5 in Appendix show the regressions of electoral behavior on the treatment (key regressions are difference-in-differences on the levels - specification 2). Since all our dependent variables are binary we use Probit estimations. As before, for each outcome variable, we begin by showing the simple difference-in-differences regression with geographical fixed effects; then we add controls for individual demographic and attitudinal characteristics. All regressions allow for correlation of errors at the enumeration area level. We focus on voter turnout and voting patterns in the presidential and gubernatorial elections, these being the elections where the stakes were highest (where the executive powers are concentrated). As in Chart 3 we compare intended behavior with reported actual behavior.

One of our key results concerns the effect of violence on turnout. Recall that we measure the change from stated intentions to vote to actual behavior as reported after the election and that overall almost a quarter of those who voted had done so despite a prior intention not to vote. The main purpose of the campaign was to persuade people who had decided not to vote because of intimidation to vote after all. Since we can already reasonably conclude that the campaign achieved its intended effect, we can interpret this effect of the campaign on turnout as being qualitatively the opposite of the effect of electoral violence itself ${ }^{18}$.

\footnotetext{
${ }^{18}$ However, the campaign also had a secondary purpose: to turn violence into a vote-loser for those politicians who espoused it. While the former effect would raise the turnout of those who had been intimidated, the latter effect could reduce the turnout of those who had planned to support candidates who espoused violence. Hence, the change in overall turnout is the net result of these two offsetting effects.
} 
We find that the primary purpose of the campaign succeeded: the proportion of people who changed their mind and voted was 9\% larger in the treated group, an effect that is significant at the $10 \%$ level. Since the campaign merely reduced rather than eliminated the threat of violence it is a lower bound estimate of the effect of violence. Indeed, we can go beyond this lower-bound estimate as follows. We proxy violence by our most specific measure, namely 'security from violence originated by politicians at the local level', defined on a 6-point scale, and estimate its effect on voter turnout, instrumenting 'security' with the treatment as in specification 3 above. With this IV approach we target the effect of violence on turnout, a much larger effect: turnout increases by $10 \%$ for each unit of security. This suggests that electoral violence was an effective strategy in keeping those likely to vote for opponents away from the polls. In turn, this may help to account for why it was used by politicians.

We now turn to the effects of the campaign on each party's score. We find that in the presidential election the campaign reduced the vote for the $\mathrm{AC}$ by $4 \%$, an effect significant at the $5 \%$ level. Recall that the AC was the weakest of the three parties (nationally) and its presidential candidate was portrayed in the media as espousing instability. The reduced vote for the AC is evidence that the secondary objective of the campaign also seems to have worked: people who had initially planned to support the AC decided to punish it whether by abstention or switching their vote to other parties. The other two main presidential candidates' scores are not significantly changed by the campaign.

At the gubernatorial elections the campaign increased the vote of the PDP by $13 \%$, an effect significant at the 5\% level. However, we might expect violence in the gubernatorial elections to vary state-by-state. Even if violence is a strategy of the weak, not all weak gubernatorial candidates might resort to it. We certainly find substantial variation: the overall effects are due to only three of the six states. In Rivers the PDP gained as a result of the campaign by a clear $25 \%$, significant at $1 \%$. In Oyo and Plateau the PDP gained almost as much, by $21 \%$ and $19 \%$ respectively. In all three states the PDP was the incumbent. We do not find significant effects for second and third parties at the state level ${ }^{19}$.

\footnotetext{
${ }^{19}$ Indeed, several sources point to the importance of electoral violence by marginal groups without a clear affiliation to the main parties. For instance, in Oyo state, Human Rights Watch underlined the role of violent groups within PDP, defeated in its primary elections. For further details, see 'Criminal Politics: Violence, 'Godfathers', and Corruption in Nigeria', October 2007. In addition, the International Foundation for Electoral Systems (IFES), who implemented nationwide surveys during the 2007 Nigerian elections, considers $40 \%$ of the electoral violence to be originating outside the main parties, PDP, AC, and ANPP ('A Nigerian Perspective on the 2007 Presidential and Parliamentary Elections', August 2007).
} 
In the final part of Table 4, we test the effects of the treatment on the specific patterns of vote change for the two parties that seem to be identified above as the ones that concentrated experimental action (PDP and AC). Namely, we test whether the treatment led voters to move from AC to abstention and to PDP (presidential elections), and to move to PDP from abstention and from AC (gubernatorial elections). We find evidence consistent with all these effects, although only moves from and to abstention are statistically significant.

\subsection{Robustness}

We now undertake three sets of robustness tests: the first regards testing for 'conformity biases' in survey data, both for violence outcomes and for voting behavior measures; the second asks whether there is a specific demographic profile that was particularly affected by the campaign both in respect of its attitudes towards violence and its voting behavior; the third tests for contamination of control areas by the treatment.

On conformity, we may still be concerned that our survey measurement of violence and voting behavior outcomes may be affected by a tendency of respondents to adapt to specific survey conditions (potentially perceived as) correlated with the treatment.

First we test the robustness of the effects of the treatment on violence outcomes - the direct mechanism of our experiment. We compare, within treatment areas (only), panel respondents, who faced the whole experimental machinery, namely two rounds of the survey and direct contact with campaigners, with the post-election oversample subjects. The subjects of the oversample were approached only for the second round of the survey and had no direct contact with campaigners, although they may still have seen the street activities and been generally aware (through their network) of the campaign. We assume that oversample respondents are less constrained to conform than panel subjects.

Table A6 in Appendix 3 reports results of difference-in-differences regressions for the questions in Table A3 asked both to the core respondents and to the oversample. For most measures there are no statistically significant effects of being approached directly. Of course, even were there to be differences these might be due to the effectiveness of direct contact rather than to higher conformity by the panel respondents. This is clearly the case for knowledge of ways to counteract 
violence (significant at the $10 \%$ level). However, since overall the differences are negligible we can reasonably reaffirm that conformity biases were not severe.

Second we direct efforts into assessing the solidity of our effects on voting behavior. Here we use a thorough module of our survey measurement on social networks. We asked each respondent about 'regularly chatting with' and about 'family links to' each of the other subject households in our survey (including the treatment oversample). Moreover, we collected, through detailed enumeration area maps, the physical distances between each subject household at each survey location. These three measures of connectedness between the elements of our sample are used to identify, for each subject, the other $n$ closest subjects. This information is used to correlate the voting behavior of the respondents with that of their close networks. Fitted values instead of actual responses per subject are used in the dependent variable to assess the robustness of the effects of the treatment. This exercise clearly assumes that true voting behavior is correlated within a network but that measurement biases are not. If the treatment effects are maintained, which we show is the case, we may be more secure in dismissing the possibility of measurement biases that are correlated across networks in the original data (which we hope to take out by performing this exercise).

We find in Table A7 (Appendix) that indeed all main treatment effects, on increasing voter turnout, decreasing AC's performance in the presidential election, and on benefitting the incumbents in the gubernatorial election, are maintained. We focus on 'chatting' as our preferred measure of connectedness of respondents, but also show results using all three alternative variables. The physical distance measure (identifying closest links for almost all respondents) allows us to increase the number of observations in the regressions. However it also adds some noise (since our geographical measure embeds many 'close' relationships that do not mean real interaction), which generally translates into larger standard errors in the estimates.

We next check whether there is a particular demographic profile that was particularly affected by the campaign: both attitudes and voting behavior changing at the same time (Table A8 in Appendix). For this we focus on those dependent variables where we have already found a clear effect and introduce demographic variables as interactions with the explanatory variables deployed previously. Note that for changes in voting the dependent variable is defined on the range 1,0 , or -1 , corresponding to a change towards party $\mathrm{X}$, no change, and a change from party $\mathrm{X}$, respectively: we therefore use Ordered Probit. We found that the characteristics most 
associated with both a change in perceptions of violence and in voting behavior in response to the campaign were respondents in smaller households, working outside the home, not owning land, and of Yoruba origin. The fact that our results rest upon an identifiable group of people who were particularly susceptible to the campaign strengthens confidence in our interpretation of the mechanism: a change in attitudes leading to a change in behavior.

Finally we test for contamination of control areas (Table A9 in Appendix) by regressing our main outcomes of interest (on violence and on voting behavior) on distance to closest treatment area, while using control location observations only. Although for most regressions we do not find significant effects, there seems to be some evidence of contamination for intensity of violence (journals measurement), empowerment, and knowledge of ways to counteract violence. This leads us to conclude that the treatment effects estimated earlier regarding these outcomes may be underestimated.

\section{Conclusion}

Since the fall of the Soviet Union there has been a proliferation of elections in societies with weak governance. In many of these societies electoral competition has produced serious levels of violence. Our study is the first to have investigated the causes and consequences of electoral violence using experimental methods. The context for our experiment, the Nigerian presidential elections of 2007, was the largest African election to date; it was fought over the highest stakes in Africa: political control of Nigerian oil revenues; and it was indeed violent. We have shown that this violence systematically reduced voter turnout. More surprisingly, it was systematically associated with non-incumbent groups. The two other important illegitimate strategies of gaining votes, ballot fraud and vote-buying, were both rife alongside violence, but these were employed quite differently. They seem to have been used predominantly by the incumbent party and deployed most vigorously where the electoral contest was expected to be particularly tight. This pattern is consistent with the incumbent party having an absolute and comparative advantage in ballot fraud, due to control of the count, and in vote buying, due to the scope for embezzlement of public resources. All three illegitimate methods were used strategically. Ballot fraud and vote buying were election-winning strategies whereas political violence appears to have been a strategy of desperation by the weak and thus somewhat analogous to terrorism. 
Finally, the success of the campaign suggests that violence can be countered. This is of direct importance: in both the Nigerian and the (also prominent) Kenyan elections of 2007 several hundred lives were lost. If violence is used by candidates who cannot win, what is its rationale? Our best hypothesis is that it strengthens the candidate's post-election position. However, electoral violence is unlike terrorism in one important respect. With terrorism the violence is the signal of power, whereas with electoral violence the election result is the signal: violence is used instrumentally to improve the result. Voter intimidation works by lowering the turnout for other candidates, thereby increasing the share of the violent candidate. We have demonstrated that the primary component of our campaign succeeded in countering the reduction in turnout. It did this by emboldening people not to be intimidated by threats. However, a campaign aimed only at emboldening people cannot hope to eliminate the power of threats to intimidate. Thus, this objective of the campaign can merely make voter intimidation less effective. The induced response of those politicians using violence may be to divert effort to other strategies, but it could instead be to increase threats so as to counter the reduced efficiency. This is the significance of the other component of the campaign: to reduce the vote of violent candidates. This also succeeded. Unlike the anti-intimidation message, the message not to vote for violent candidates has the potential to make violence counter-productive. We have demonstrated that a dual-purpose campaign can successfully deliver both messages. An implication is that political violence can be effectively countered by a rather straightforward measure. 


\section{References}

Achebe, Chinua (1983), The Trouble with Nigeria, Heinemann Educational Publishers;

Bikhchandani, Sushil, David Hirshleifer, and Ivo Welch (1992), A Theory of Fads, Fashion, Custom, and Cultural Change as Informational Cascades, Journal of Political Economy, 100(5), pp. 992-1026;

Bikhchandani, Sushil, David Hirshleifer, and Ivo Welch (1998), Learning from the Behavior of Others: Conformity, Fads, and Informational Cascades, Journal of Economic Perspectives, 12(3), pp. 151-170;

Becker, Gary S. (1983), A Theory of Competition among Pressure Groups for Political Influence, Quarterly Journal of Economics, 98(3), pp. 371-400;

Besley, Timothy (2006), Principled Agents? The Political Economy of Good Government, Oxford University Press;

Besley, Timothy, and Masayuki Kudamatsu (2007), Making Autocracy Work, CEPR Discussion Paper 6371;

Brusco, Valeria, Marcelo Nazareno, and Susan C. Stokes (2004), Vote Buying in Argentina, Latin American Research Review, 39(2), pp. 66-88;

Collier, Paul and Benedikt Goderis (2007), Commodity Prices, Growth, and the Natural Resource Curse: Reconciling a Conundrum, Oxford University, Working Paper.

Collier, Paul and Anke Hoeffler (2008), Testing the Neo-Con Agenda: Democracy in ResourceRich Societies, European Economic Review, forthcoming;

Collier, Paul and Dominic Rohner (2008), Democracy, Development, and Conflict, Journal of the European Economic Association, 6(2-3): 531-540.

Dixit, Avinash, and John Londregan (1996), The Determinants of Special Interests in Redistributive Politics, Journal of Politics, 58(4), pp. 1132-1155;

Gerber, Alan S. (2004), Does Campaign Spending Work? Field Experiments Provide Evidence and Suggest New Theory, American Behavioral Scientist, 47(5), pp. 541-574;

Gerber, Alan S. and Donald P. Green (2000), The Effects of Canvassing, Telephone Calls, and Direct Mail on Voter Turnout: A Field Experiment, American Political Science Review, 94(3), pp. 653-663;

Groseclose, Tim, and James M. Snyder, Jr. (1996), Buying Supermajorities, American Political Science Review, 90(2), pp. 303-315;

Grossman, Gene M., and Elhanan Helpman (1996), Electoral Competition and Special Interest Politics, Review of Economic Studies, 63(2), pp. 265-286;

Kudamatsu, Masayuki (2006), Has Democratization Reduced Infant Mortality in Sub-Saharan Africa? Evidence from Micro Data, University of Stockholm, IIES, Working Paper;

Kuran, Timur (1989), Sparks and Prairie Fires: A Theory of Unanticipated Political Revolution, Public Choice, 61, pp. 41-74;

Kuran, Timur (1991), The East European Revolution of 1989: Is it Surprising that We Were Surprised?, American Economic Review Papers and Proceedings, 81(2), pp. 121-125; 
Lohmann, Susanne (1994), The Dynamics of Informational Cascades: The Monday Demonstrations in Leipzig, East Germany, 1989-91, World Politics, 47(1), pp. 42-101;

Lohmann, Susanne (2000), Collective Action Cascades: An Informational Rational for the Power in Numbers, Journal of Economic Surveys, 14(5), pp. 655-684;

Maier, Karl (2000), This House Has Fallen: Nigeria in Crisis, Westview Press;

Mehlum, Halvor, Karl Moene and Ragnar Torvik (2006), Institutions and the Resource Curse, The Economic Journal, 116(508), pp. 1-20;

McMillan, John and Pablo Zoido (2004), How to Subvert Democracy: Montesinos in Peru, Journal of Economic Perspectives, 18(4), pp 69-92;

Robinson, James A., Ragnar Torvik and Thierry Verdier (2006), Political Foundations of the Resource Curse, Journal of Development Economics, 79(2), pp. 447-468;

Sachs, Jeffrey D. and Andrew M. Warner (1995), Natural Resource Abundance and Economic Growth, NBER, Working Paper 5398;

Smith, Daniel Jordan (2007), A Culture of Corruption: Everyday Deception and Popular Discontent in Nigeria, Princeton University Press;

Vicente, Pedro C. (2006), Does Oil Corrupt? Evidence from a Natural Experiment in West Africa, Oxford University, Working Paper;

Vicente, Pedro C. (2007a), Is Vote Buying Effective? Evidence from a Field Experiment in West Africa, Oxford University and BREAD, Working Paper;

Vicente, Pedro C. (2007b), Corrupted Scholarships, Oxford University, Working Paper;

Wantchekon, Leonard (2003), Clientelism and Voting Behavior: Evidence from a Field Experiment in Benin, World Politics, 55, pp. 399-422. 


\section{Appendix 1: Fieldwork}

\section{Treatment Design}

The anti-violence campaign reached 12 enumeration areas (neighborhoods or villages). As referred, this was a random choice within the chosen 6 states of Nigeria. The randomization was conducted by the authors. It was implemented by ActionAid International Nigeria (AAIN http://www.actionaid-nigeria.org/) during a two-week period, February $13^{\text {th }}$ to $27^{\text {th }}, 2007$, just after the baseline survey.

AAIN is Nigeria's chapter of global ActionAid, headquartered in South Africa, with total budget USD $133 \mathrm{~m}$ in 2005, and specializing on Community Improvement and Capacity Building - it was ranked 20th worldwide in terms of 'performance' in a recent list compiled by Financial Times/Dalberg of global organizations devoted to philanthropy (above Transparency International, UNDP, or Amnesty International) ${ }^{20}$.

For this campaign, AAIN worked with local state-level partner NGOs, who actually conducted the campaign activities in the field. The authors of the paper supervised operations in the field in 4 out of the 6 states involved in this campaign. Since each state was allocated a different team of campaign fieldworkers, campaign activities were fully contemporaneous in all states.

The campaign consisted of a clear message against electoral violence, embedded in the main slogan ('No to political violence! Vote against violent politicians.'). The main guidelines of the campaign were discussed with the authors, the central AAIN officers, and the local partnering NGO representatives. Actual material and activity design was undertaken with the help of a specialized firm in Abuja.

The slogan of the campaign was written in a wide range and large quantity of distributed campaign materials: t-shirts (3,000, i.e. 1 for every 2 households in treated locations on average), caps $(3,000)$, hijabs for Muslim women $(1,000)$, leaflets $(5,000)$, posters $(3,000)$, and stickers $(3,000)$ - images for the leaflets/posters and stickers are displayed in Appendix 2, Figure A1. Note that these means of campaigning are the ones primarily chosen by politicians in Nigeria to

${ }^{20}$ See the Financial Times, July $5^{\text {th }}$, 2007, Report on 'Corporate Citizenship and Philanthropy'. 
licitly spread awareness about their candidacies. The campaign also included road shows. These were used to help widening the coverage of the main message and the distribution of materials (particularly important in urban locations), and included jingles in Yoruba, Hausa, and Pidgin English.

The campaign was however designed to work mainly through the holding of town meetings and popular theatres. The town meetings were designed to provide an opportunity for grassroots to meet with local representatives for finding ways of counteracting politically-motivated violence theoretically they were built to minimize the collective action problem that is associated to finding effective ways of diminishing conflict at the local level. Popular theatres were based on the same script for all states (featuring one good and one bad politician, with the bad one instilling violent intimidation), and were designed to target youths (usually the ones providing labor for violent activities) and other audiences (e.g. women) not as easy to recruit for town meetings ${ }^{21}$. The campaigners were instructed to primarily target panel respondents (i.e. baseline subjects $^{22}$ ), not only in terms of distribution of materials, but also in terms of invitations to attending the town meetings and the popular theatres.

The campaign broadly happened in orderly terms, without substantial obstacles, in a timely manner. Some examples of the worst problems confronted are given in the following passages of state-level reports:

Any campaign in Warri cannot be carried out without police involvement. As such the Divisional Police Officer was contacted; five police officers were allotted for the campaign at Ogiame Primary School. [...] The campaign went on smoothly. - Delta state.

'The last day of the campaign in Rukpakwolusi witnessed the storming of the community by militants of the Niger Delta People Volunteers Force shooting sporadically into the air in a convoy of vehicles at the exact location where the community had gathered to witness the campaign drama. When the militants

\footnotetext{
${ }^{21}$ A report of the campaign, including systematic photos and films for each state's campaign activities is available from http://www.iig.ox.ac.uk/iig/research/09-political-violence-nigeria/. These include a thorough depiction of the all campaign materials and activities.

${ }^{22}$ At least one campaign representative accompanied the survey team during the pre-election survey, primarily for site identification, and respondent addresses were shared with the campaigners at that stage.
} 
alighted from their vehicles, some of them recognized the presence of Commonwealth of Niger Delta Youths leadership at the venue and actually did not harass anybody, but requested that campaign materials should be distributed to them. That was complied on the directive of the state project coordinator.' Rivers state.

'The thug nature of Kasuwan-nama community [part of North Jos treatment enumeration area] members disturbed the fluid process the campaign anticipated. The most scary part was the sharing of campaign materials which resulted into a rowdy situation until we were forced to exit the scene.' - Plateau state.

\section{Sampling}

Our field experiment included 24 locations/enumeration areas. These were chosen within Afrobarometer's (http://www.afrobarometer.org/) representative sample of all 36 states of Nigeria that served in their 2007 pre-election survey (contemporaneous to ours). Their sample choice used census data (i.e. weighted by the distribution of households) and corresponding enumeration areas (all averaging approximately 500 households). It included 301 enumeration areas.

Our sampling has a non-random component as we chose 2 states in each of the three main regions of the country (Southwestern, Southeastern, and Northern), by looking at the recent history of politically-motivated violence. Namely we used reports by Human Rights Watch ${ }^{23}$, ActionAid International, and other independent sources. This process led to choosing Lagos and Oyo (Southwestern), Delta and Rivers (Southeastern), and Kaduna and Plateau (Northern). This option revealed our emphasis on studying violence over studying the 'country' (which would be achieved under a representative choice of states), while keeping the basic, traditional diversity of the country - very much borrowed from the conventional ethnic predominance of Yoruba in the southwest, Igbo in the southeast, and Fulani/Hausa in the north.

The remaining stage of the sampling process was purely random. We began by randomly choosing 2 'treated' enumeration areas in each of the 6 states from Afrobarometer's list. Then we chose 'control' areas by selecting the closest locations from each of the 'treated' that were in

\footnotetext{
${ }^{23}$ See for instance Human Rights Watch, 'Testing Democracy: Political Violence in Nigeria', April 2003, 'Nigeria's 2003 Elections: the Unacknowledged Violence', June 2004.
} 
Afrobarometer's list and that were of the same type in terms of the classification 'large urban', 'small urban', and 'rural' (stemming from the census). This process led to choosing the areas shown in Map A1, Appendix 2.

The data-gathering fieldwork was performed jointly with Afrobarometer and their long-standing Nigerian partner Practical Sampling International (PSI) for the baseline survey. At that time, households within a census area were chosen randomly using Afrobarometer's standard techniques (e.g. by choosing the $\mathrm{n}^{\text {th }}$ house). Then the conditions for sampling within a household were: 18 years of age or higher, residence in the corresponding enumeration area. In the baseline we interviewed 1200 respondents (50 per enumeration area) in the period January $20^{\text {th }}$ to February $3^{\text {rd }}, 2007$.

In the post-election survey, we were on the field through PSI, though not involving Afrobarometer's explicit collaboration. At that time we sought to visit the same respondents that were included in the sample for the baseline - we could re-survey 1149 (96\%) of those subjects in the period May $22^{\text {nd }}$ to June $5^{\text {th }}, 2007$. During the same time frame, we gathered a fresh sample of 300 respondents in treated enumeration areas ( 25 per enumeration area), what we will refer to as the treatment post-election oversample. The only additional requirement for this group's sampling procedure (apart from the referred standard rules) was that they were 'not directly approached' by the campaign team. This way we made sure that this group could serve as a control group within treatment areas for direct campaigning.

The authors supervised the whole fieldwork, and were in-field during training and piloting of the surveys.

\section{Questionnaire Design}

On questionnaire design, while the baseline was jointly designed with Afrobarometer, therefore including some modules that are not related with our field experiment (e.g. public opinion questions), the post-election instruments (panel and oversample) were fully targeting this experiment. ${ }^{24}$ This setting implied that in the post-election surveys we could include a larger number of questions related to our measurements of interest (e.g. including extended demographics). The basic structure of questionnaires was however untouched across different

${ }^{24}$ All questionnaires are available upon request to the authors. 
instruments, including by order, demographics, the different measures of violence, information about elections, and self-reported electoral preferences/behavior.

Note that most prominently on violence, the majority of the questions featured a subjective scale. These scales (usually) had an odd number of options, were approached verbally using qualifiers (not numbers), and were read in a stepwise manner. For instance, the question 'How secure against violence originated by politicians has been your neighborhood or village?' embedded 7 possible answers ranging from 'Extremely insecure' to 'Extremely secure', with middle answers 'neither insecure nor secure', and 'somewhat', 'very' insecure/secure. These options were approached first by referring to a 3-point scale: 'insecure', 'neither insecure nor secure', and 'secure'. Then, depending on the answer, the enumerator could deepen one of the sides. This careful and balanced way of reading scales gives us some assurance that original question-scales were perceived linearly by respondents.

\section{The Postcard Variable}

One of the measurements that only took place during the post-election period was the one relating to our 'postcard variable'. During the interview in the post-election surveys (panel and oversample), we provided the respondents with a pre-stamped (ready-to-mail) postcard - the main side of the postcard is shown in Appendix 2, Figure A2 (it was addressed to PSI in Lagos on the other side and did not require the sender to identify him/herself). Enumerators explained to respondents that sending the card would contribute to having the sponsors of this project highlight the concern for the problem of political violence in the respondent's state. Each postcard was numbered and we could therefore identify the sender. We interpret the sending of this postcard as an incentive-compatible measure of empowerment to counteract violence, as it embedded an individual cost of taking the postcard to a post office ${ }^{25}$.

\footnotetext{
${ }^{25}$ We nevertheless control for obvious determinants of postcard sending like income and distance to post office.
} 
Appendix 2: Field Materials and Sample

Figure A1: Leaflet/Poster (above) and Sticker (below)
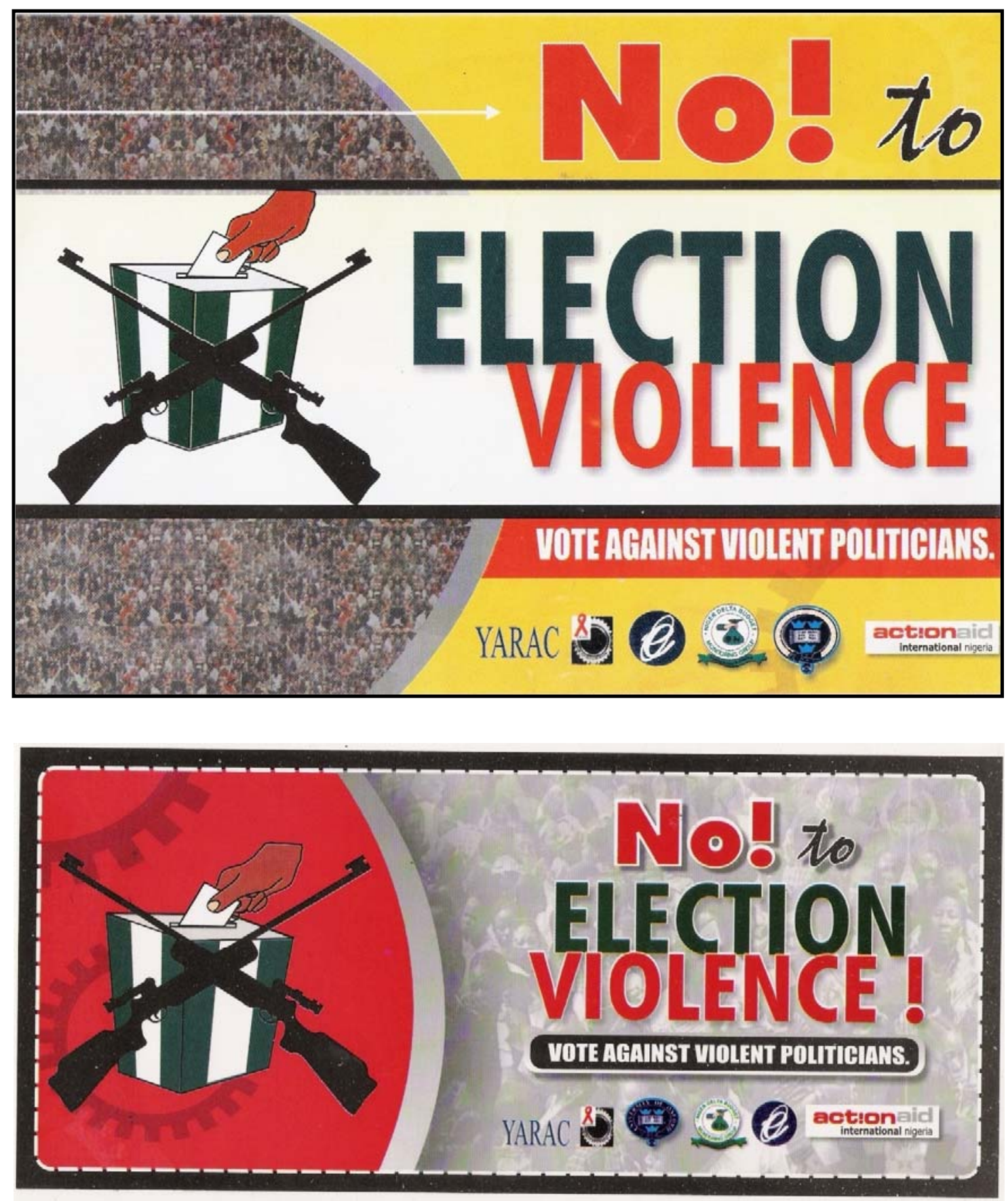
Figure A2: Postcard

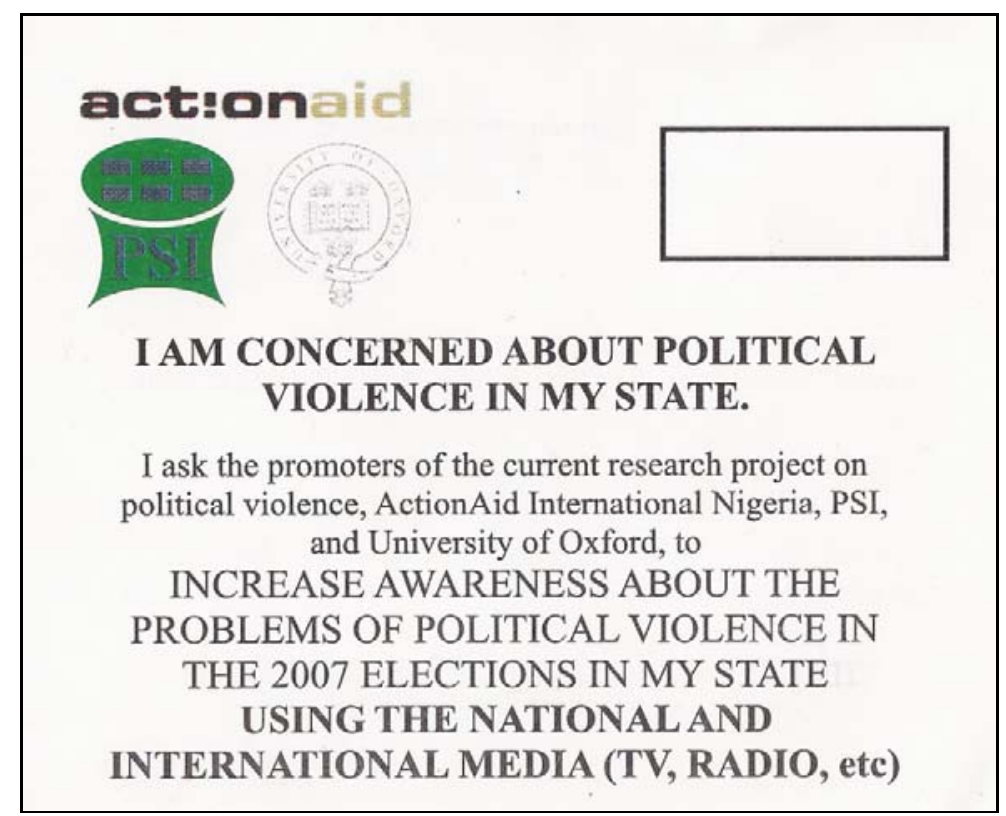




\section{Nigeria - Sampled Enumeration Areas}

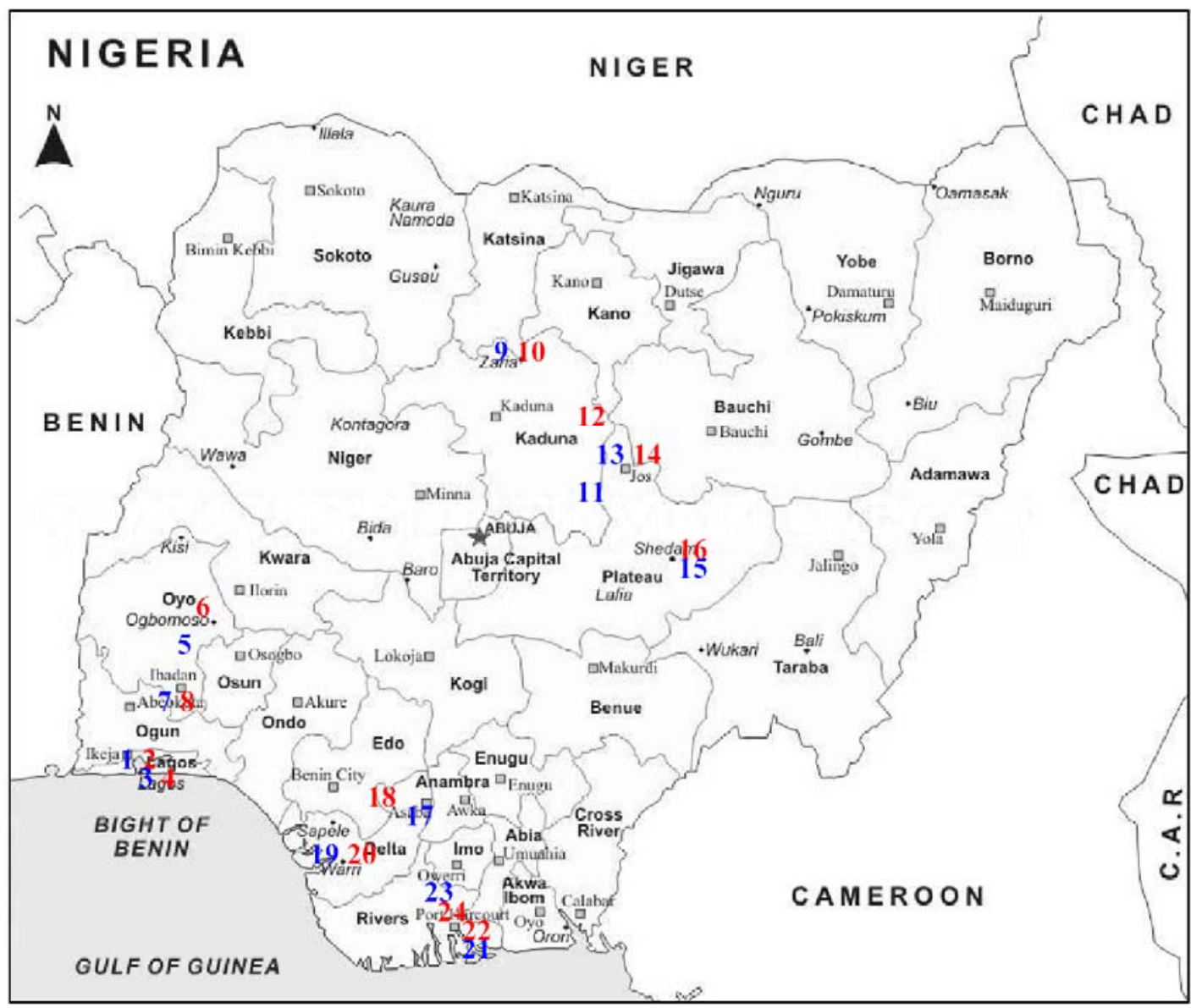

Legend: Treatment Area, Control Area; LU: Large Urban; SU: Small Urban; R: Rural

\begin{tabular}{|l|}
\hline \multicolumn{1}{|c|}{ SOUTHWEST REGION } \\
\hline Oyo: \\
5. Atiba - Ajagba SU \\
6. Ogbomosho North - Jagun Oke. SU \\
7. Ibadan Southwest - Jericho LU \\
8. Ibadan Southwest - Ring Road LU \\
\hline Lagos: \\
1. Alimosho - Akwonjo LU \\
2. Alimosho - Ikotun LU \\
3. Lagos Mainland - Ebute Met. LU \\
4. Lagos Island - Lagos Island LU \\
\hline
\end{tabular}

\begin{tabular}{|l|}
\hline \multicolumn{1}{|c|}{ NORTH REGION } \\
\hline Kaduna: \\
9. Zaria - Zaria (150) LU \\
10. Zaria - Zaria (151) LU \\
11. Kaura - Amawa Tudun Wada R \\
12. Lere - Abadawa Laga Akwai R \\
\hline Plateau: \\
13. Jos North - Jos (78) LU \\
14. Jos North - Jos (77) LU \\
15. Quan-Pan - Piya R \\
16. Quan-Pan - Pandam R \\
\hline
\end{tabular}

\begin{tabular}{|l|}
\hline SOUTHEAST REGION \\
\hline Delta: \\
17. Oshimili North - Oko Anala R \\
18. Ika South - Obi Anyima R \\
19. Warri South - Warri (290) LU \\
20. Warri South - Warri (289) LU \\
\hline Rivers: \\
21. Andoni - Agama R \\
22. Eleme - Sime-Tai R \\
23. Obio/Akpor - Rukpakwolusi R \\
24. Gokana - Nugbe-Yeghe R \\
\hline
\end{tabular}




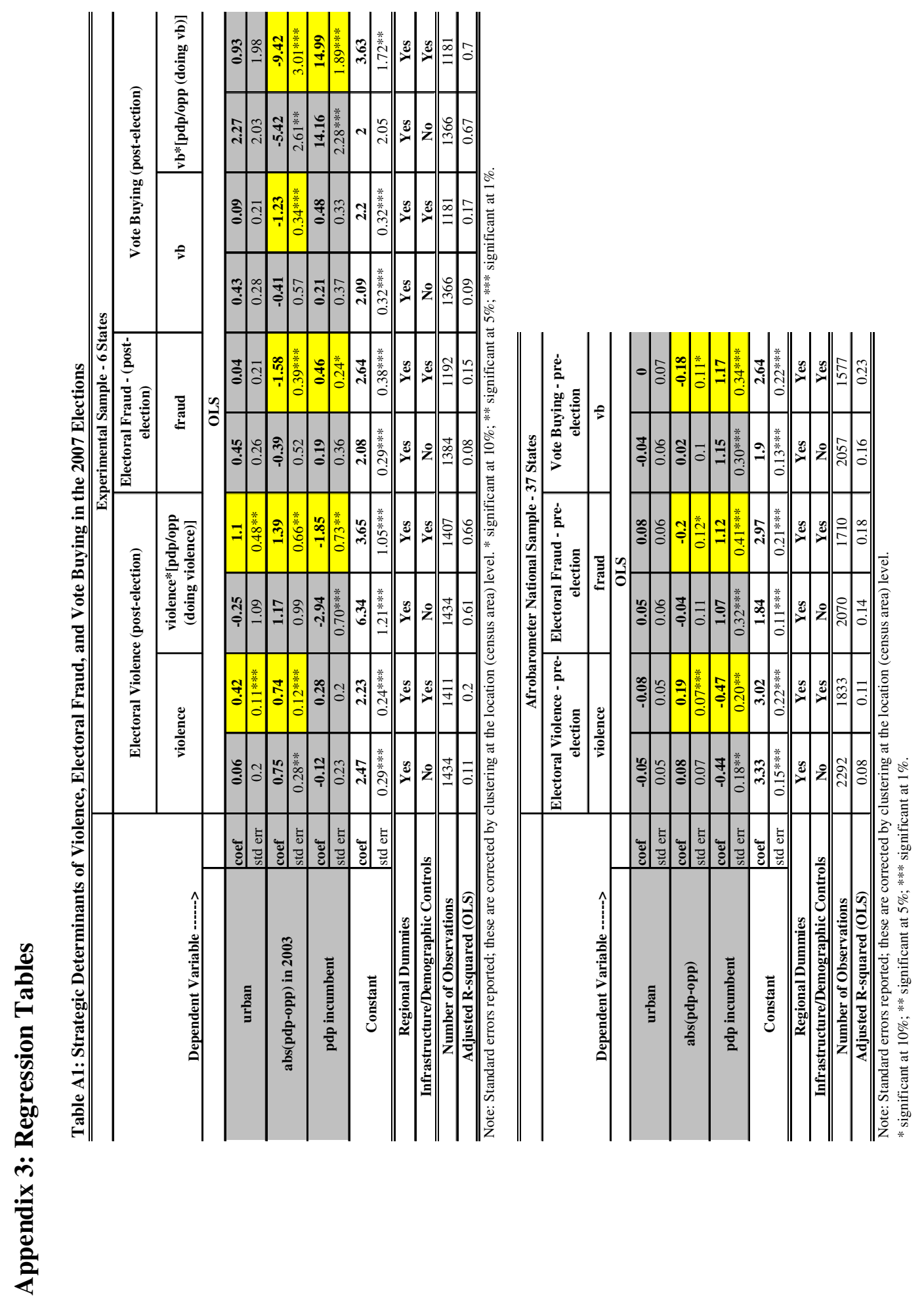


Table A2: Differences across Treatment and Control Areas - Demographics (Panel plus Oversample)

\begin{tabular}{|c|c|c|c|c|c|}
\hline & & Control & Treatment & Difference & $\begin{array}{c}\text { Number of } \\
\text { Observations }\end{array}$ \\
\hline \multirow{12}{*}{ Basic Demographics } & \multirow{2}{*}{ female } & \multirow{2}{*}{0.5} & \multirow{2}{*}{0.5} & $\mathbf{0}$ & \multirow{2}{*}{1500} \\
\hline & & & & 0 & \\
\hline & \multirow{2}{*}{ age } & \multirow{2}{*}{32.95} & \multirow{2}{*}{32.69} & -0.26 & \multirow{2}{*}{1497} \\
\hline & & & & 1.01 & \\
\hline & \multirow{2}{*}{ household size } & \multirow{2}{*}{6.43} & \multirow{2}{*}{6.46} & 0.03 & \multirow{2}{*}{1500} \\
\hline & & & & 0.74 & \\
\hline & \multirow{2}{*}{ single } & \multirow{2}{*}{0.38} & \multirow{2}{*}{0.42} & 0.04 & \multirow{2}{*}{1449} \\
\hline & & & & 0.05 & \\
\hline & married & 0.58 & 0.55 & -0.03 & 1449 \\
\hline & marriea & 0.58 & 0.53 & 0.04 & 1449 \\
\hline & scheoling (0-9) & 431 & 483 & 0.52 & 1500 \\
\hline & schooning $(0-Y)$ & 4.51 $>>>>3$ & 4.00 & 0.34 & 1000 \\
\hline & varubr & 32 & 028 & -0.04 & 1500 \\
\hline & yoruba & 0.32 & 0.28 & 0.17 & 1500 \\
\hline & houce & 016 & 01 & -0.06 & 1500 \\
\hline & nausa & 0.10 & 0.1 & 0.11 & 1300 \\
\hline & i. & $007-725$ & 016 & 0.09 & 1500 \\
\hline Fthnicity and Roligion & 1900 & 0.07 & 0.10 & 0.09 & 1500 \\
\hline Ectictity ana kengion & christian & 062 & 074 & 0.12 & 1499 \\
\hline & cnristian & 0.02 & 0.14 & 0.13 & 1499 \\
\hline & . & 0 & 005 & $\begin{array}{l}-0.09 \\
\end{array}$ & 1400 \\
\hline & musmim & 0.54 & 0.25 & 0.13 & 1499 \\
\hline & religious intencity 1 (1) & 76 & 507 & 0.31 & 1485 \\
\hline & rengious mitensty (1-0) & $4 . / 0$ & 5.01 & 0.2 & 1403 \\
\hline & iob chobility $\left(\mathbf{0}_{3} 3\right)$ & 136 & 141 & 0.05 & 1500 \\
\hline & Job stabminy $(0-3)$ & 1.30 & 1.41 & 0.16 & 1500 \\
\hline & agriculture & 016 & 012 & -0.04 & 1500 \\
\hline & agricuiture & 0.10 & 0.12 & 0.07 & 1000 \\
\hline & nublic official & 0.07 & 0.07 & $\mathbf{0}$ & 1500 \\
\hline & & & & 0.01 & \\
\hline & industry/sarvices. trader & 013 & 014 & 0.01 & 1500 \\
\hline Occunation $>-1$ & maustry/services: trader & 0.13 & 0.14 & 0.03 & \\
\hline & industrv/services. artican & 011 & 013 & 0.02 & 1500 \\
\hline & Inaustry/services: artisan & 0.11 & 0.13 & 0.03 & 1500 \\
\hline & inductru/carviceser & 011 & 015 & 0.04 & 1500 \\
\hline & inaustry/services: otner & 0.11 & 0.10 & 0.04 & 1300 \\
\hline & student & 022 & 202 & $\mathbf{0}$ & 1500 \\
\hline & student & 0.22 & 0.22 & 0.04 & \\
\hline & bo & 012 & 000 & -0.03 & 1500 \\
\hline & & 0.12 & 0.09 & 0.04 & 1000 \\
\hline & house & 061 & 058 & -0.03 & 1496 \\
\hline & & & & 0.11 & \\
\hline & Jand & 0.53 & 0.56 & 0.03 & 1494 \\
\hline & & & & 0.12 & \\
\hline & cattle & 033 & 037 & 0.04 & 1495 \\
\hline & Catte & 0.35 & 0.37 & 0.1 & 1495 \\
\hline & tv & 063 & 72 & 0.09 & 1407 \\
\hline & IV & $0.0 \mathrm{Y}$ & 0.12 & 0.11 & \\
\hline Property and & ali & 000 & 002 - & 0.04 & 1400 \\
\hline Expenditure & raaio & 0.89 & 0.93 & 0.03 & 1499 \\
\hline & fridge & 029 & 037 & 0.08 & 1496 \\
\hline & Iriage & 0.29 & 0.37 & 0.11 & \\
\hline & land phone & 0.1 & 0.1 & $\mathbf{0}$ & 1496 \\
\hline & & 0.1 & 0.1 & 0.05 & \\
\hline & coll nhone & 051 & 058 & 0.07 & 1496 \\
\hline & cen pnone & 0.01 & 0.58 & 0.12 & 1490 \\
\hline & household expenditure & 10001 & 2960 & 3867 & 1262 \\
\hline & (naira/month) & 19001 & 22869 & 4759 & \\
\hline
\end{tabular}

Note: Standard errors reported; these are corrected by clustering at the location (census area) level.

$*$ significant at $10 \%$;** significant at $5 \%$; *** significant at $1 \%$. These results come from OLS regressions. 
Table A2 (continued): Differences across Treatment and Control Areas - Panel (Baseline Violence and Political Preferences, Attrition)

\begin{tabular}{|c|c|c|c|c|c|}
\hline & & Control & Treatment & Difference & $\begin{array}{c}\text { Number of } \\
\text { Observations } \\
\end{array}$ \\
\hline & \multirow{2}{*}{$\begin{array}{c}\text { free } \& \text { fair } 2003 \text { election - } \\
\text { general (1-4) }\end{array}$} & \multirow{2}{*}{3.24} & \multirow{2}{*}{3.00} & -0.24 & \multirow{2}{*}{961} \\
\hline & & & & 0.15 & \\
\hline & \multirow{2}{*}{$\begin{array}{c}\text { free } \& \text { fair } 2003 \text { election - } \\
\text { violence (1-4) }\end{array}$} & \multirow{2}{*}{2.98} & \multirow{2}{*}{2.87} & -0.10 & \multirow{2}{*}{977} \\
\hline & & & & 0.17 & \\
\hline & \multirow{2}{*}{ conflict within family $(0-4)$} & \multirow{2}{*}{0.61} & \multirow{2}{*}{0.6} & -0.01 & \multirow{2}{*}{1194} \\
\hline & & & & 0.07 & \\
\hline & \multirow{2}{*}{ conflict within community $(0-4)$} & \multirow{2}{*}{1.18} & \multirow{2}{*}{1.29} & 0.11 & \multirow{2}{*}{1184} \\
\hline & & & & 0.18 & \\
\hline & political intimidation $(0-3)$ & 0.09 & 0.1 & 0.01 & 1089 \\
\hline & 的 & 0.09 & & 0.03 & \\
\hline & influence of assassinations (1-7) & 3.35 & 3.05 & -0.3 & 1125 \\
\hline & 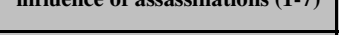 & & & 0.33 & \\
\hline & politicians advocating violence (1- & 2.9 & 3.29 & 0.39 & 1128 \\
\hline & & 2.9 & 3.29 & 0.29 & 1120 \\
\hline & thugs' violent activities & 3.03 & 2.77 & -0.26 & 1140 \\
\hline & & J.0J & 2.11 & 0.44 & 1140 \\
\hline & security (1-7) & 453 & 455 & 0.02 & 1144 \\
\hline & 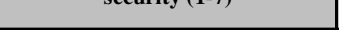 & (7.0. & (1) & 0.28 & \\
\hline & cunport for 'dl & 32 & 332 & 0.12 & 1135 \\
\hline & support ior do-or-die antar $(1-1)$ & 3.2 & 3. 2. & 0.35 & 1153 \\
\hline & standing arainst violence $(1-7)$ & 485 & 497 & 0.12 & 1136 \\
\hline Violence & 作 & 4.05 & 4.91 & 0.26 & 1100 \\
\hline Vive & empowerment against violence (1- & 425 & 481 & 0.56 & 1116 \\
\hline & \begin{tabular}{|c|} 
7) \\
\end{tabular} & 4.20 & 4.01 & $0.31^{*}$ & 1110 \\
\hline & knowledge of ways to counteract & 475 & 462 & -0.13 & 1133 \\
\hline & violence $(1-7)$ & 4.75 & 4.62 & 0.3 & 1133 \\
\hline & 'violence is iustified' (1-5) & 208 & 205 & -0.03 & 1181 \\
\hline & & & & 0.14 & \\
\hline & thefts public place (perception) (1. & 288 & 259 & -0.29 & 1142 \\
\hline & 7) & & & 0.38 & \\
\hline & thefts public place (experience) & 1.17 & 1.26 & 0.09 & 1193 \\
\hline & 4) & & & 0.06 & \\
\hline & vandalism (perception) (1-7) & 2.42 & 2.19 & -0.23 & 1130 \\
\hline & & & & 0.36 & \\
\hline & vandalism (experience) & 1.09 & 1.05 & -0.04 & 1137 \\
\hline & & & & 0.03 & \\
\hline & physical intimidation (perception) & 234 & 2.3 & -0.04 & 1145 \\
\hline & $(1-7)$ & & & 0.37 & \\
\hline & physical intimidation (experience) & 114 & 109 & -0.05 & 1195 \\
\hline & \begin{tabular}{|r}
$(1-4)$ \\
\end{tabular} & 1017 & & 0.04 & \\
\hline & nroblems with nolice (1-7) & 276 & 256 & -0.2 & 1122 \\
\hline & 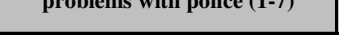 & 2.10 & 2.50 & 0.32 & 1122 \\
\hline & intensity (iournals) (1-5) & 272 & 273 & 0.01 & 57 \\
\hline & mitensity (journais) (1-5) & 2.12 & 2.15 & 0.24 & JI \\
\hline & turnout 2003 & 07 & 07 & $\mathbf{0}$ & 1174 \\
\hline & turnout $200 \mathrm{~s}$ & 0.1 & 0.1 & 0.06 & 1174 \\
\hline & ndn 2003 nresidential & 045 & 0.48 & 0.03 & 1149 \\
\hline & pap 2009 presidentual & 0.45 & 0.40 & 0.09 & 1149 \\
\hline & annn 2003 presidential & 0.16 & 0.08 & -0.08 & 1149 \\
\hline & äpp 2000 presictiotal & 0.10 & $0.0 \mathrm{o}$ & 0.08 & \\
\hline Flectoral Behavior & 2003 nresidential & 0.03 & 0.05 & 0.02 & 1149 \\
\hline 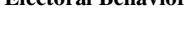 & ae 2000 PI & $0.0 \mathrm{~J}$ & $0.0 \mathrm{~S}$ & 0.02 & 1147 \\
\hline & ndn 2003 a overnor & 045 & 0.46 & 0.01 & 1149 \\
\hline & pap 2000 govet hor & $0.4 \mathrm{~J}$ & 0.40 & 0.08 & \\
\hline & annn 2003 governor & 013 & 009 & -0.04 & 1149 \\
\hline & 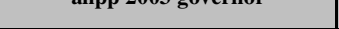 & & & 0.06 & \\
\hline & ac 2003 governor & 0.03 & 0.03 & $\mathbf{0}$ & 1149 \\
\hline & & & & 0.02 & \\
\hline Panel Attrition & panel re-surveving & 0.97 & 0.95 & -0.02 & 1200 \\
\hline & & & & 0.01 & \\
\hline
\end{tabular}

Note: Standard errors reported; these are corrected by clustering at the location (census area) level.

* significant at $10 \%$;** significant at $5 \%$; *** significant at $1 \%$. These results come from OLS regressions. 


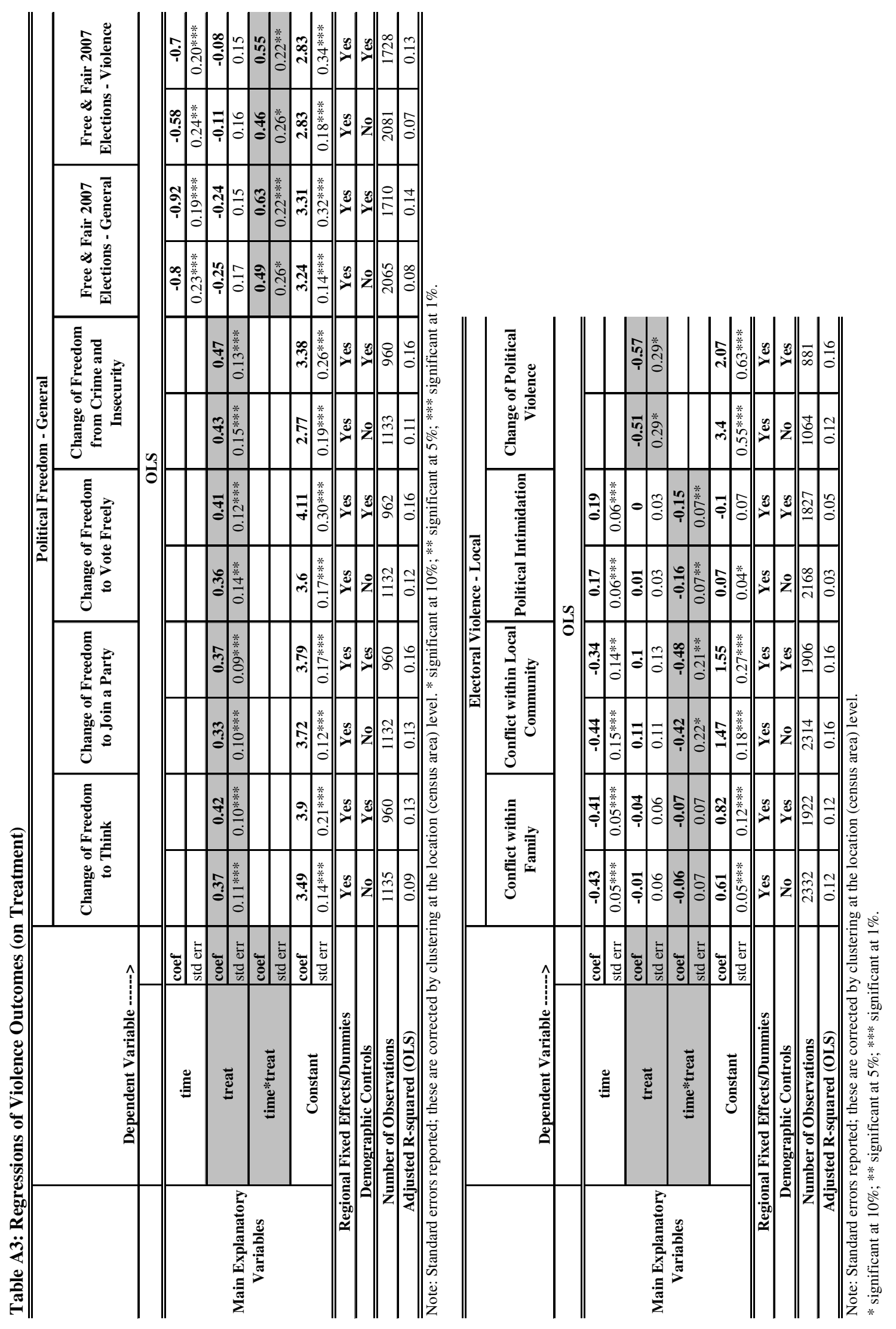



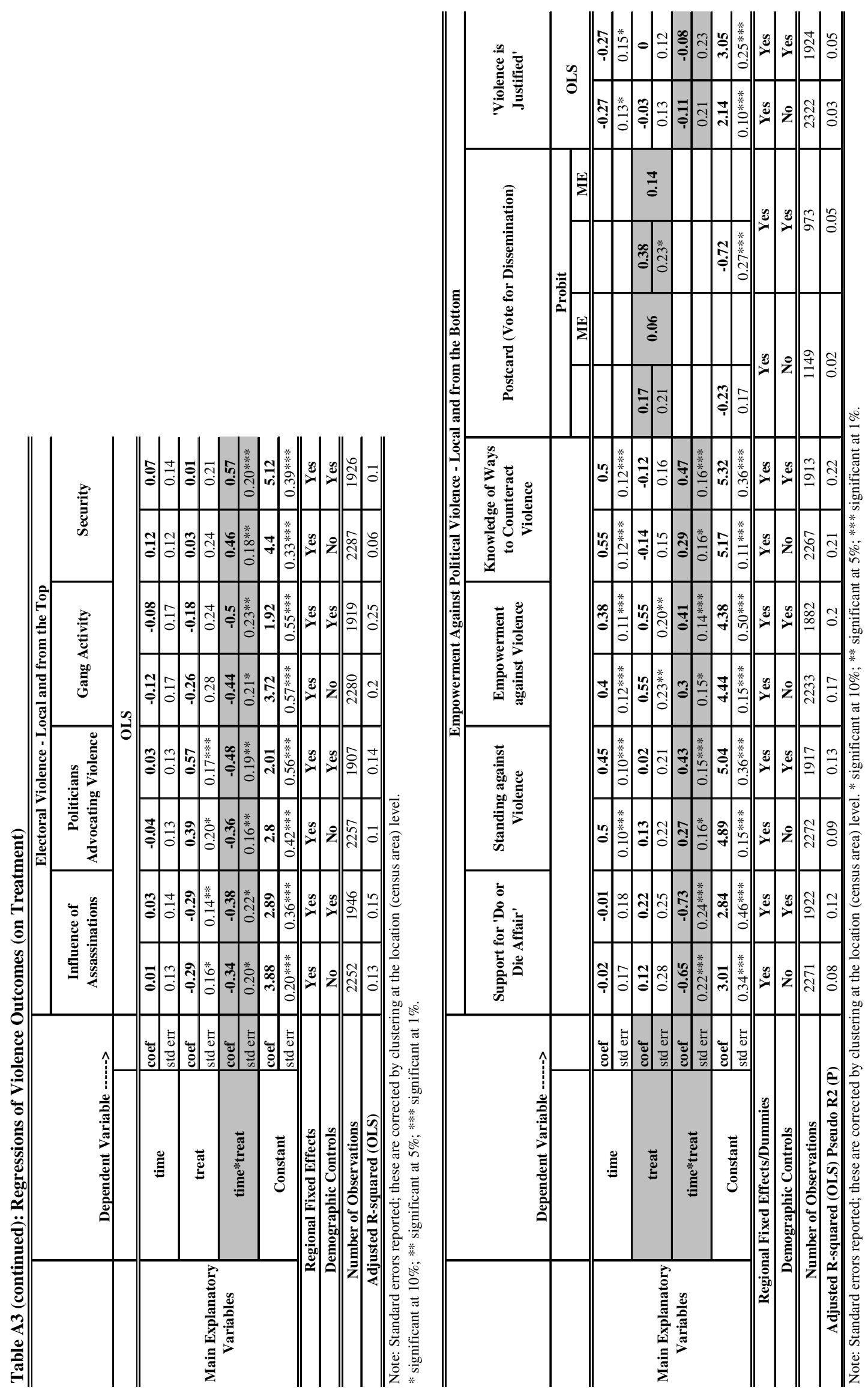


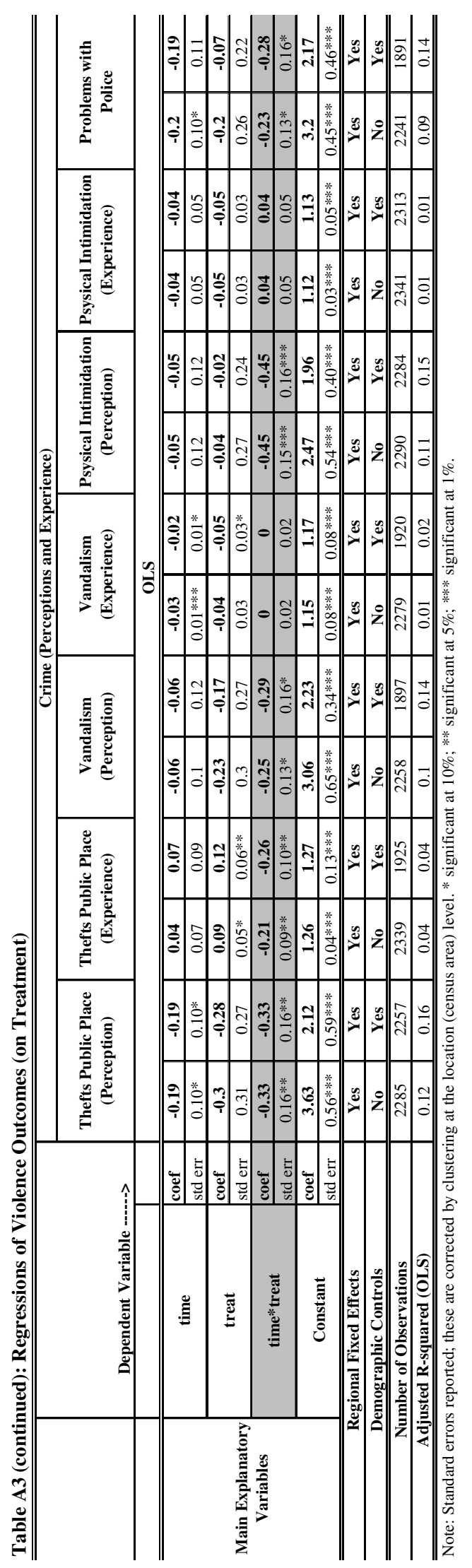


Table A4: Regressions of Violence Outcomes from Journaling (on Treatment)

\begin{tabular}{|c|c|c|c|c|c|c|c|}
\hline & \multirow{2}{*}{\multicolumn{2}{|c|}{ Dependent Variable ------> }} & \multicolumn{5}{|c|}{ Electoral Violence (Journaling) } \\
\hline & & & \multicolumn{4}{|c|}{ Intensity } & $\begin{array}{l}\text { Intensity \& } \\
\text { Incidence }\end{array}$ \\
\hline & & & \multicolumn{5}{|c|}{ OLS } \\
\hline \multirow{8}{*}{$\begin{array}{c}\text { Main Explanatory } \\
\text { Variables }\end{array}$} & \multirow{2}{*}{ time } & coef & & -0.03 & 0 & -0.01 & -0.05 \\
\hline & & std err & & 0.25 & 0.17 & 0.14 & 0.14 \\
\hline & \multirow{2}{*}{ treatment } & coef & -0.16 & 0.2 & $\mathbf{0 . 3 3}$ & 0.2 & 0.02 \\
\hline & & std err & 0.23 & 0.3 & $0.17 *$ & 0.2 & 0.22 \\
\hline & \multirow{2}{*}{ time*treatment } & coef & & -0.36 & -0.4 & -0.51 & -0.08 \\
\hline & & std err & & 0.37 & 0.28 & $0.29 *$ & 0.42 \\
\hline & \multirow{2}{*}{ Constant } & coef & 2.66 & 2.69 & 2.37 & 2.65 & 2.84 \\
\hline & & std err & $0.10^{* * * *}$ & $0.25 * * *$ & $0.18^{* * * *}$ & $0.33^{* * * *}$ & $0.34 * * *$ \\
\hline \multicolumn{3}{|c|}{ Regional Dummies } & No & No & Yes & Yes & Yes \\
\hline \multicolumn{3}{|c|}{ Location Controls } & No & No & No & Yes & Yes \\
\hline \multicolumn{3}{|c|}{ Number of Observations } & 74 & 131 & 131 & 131 & 131 \\
\hline \multicolumn{3}{|c|}{ Adjusted R-squared (OLS) } & 0 & 0 & 0.07 & 0.06 & 0 \\
\hline
\end{tabular}

Note: Standard errors reported; these are corrected by clustering at the location (census area) level.

* significant at $10 \%$; ** significant at $5 \%$; *** significant at $1 \%$. 
Table A5: Regressions of Voting Behavior (Turnout)

\begin{tabular}{|c|c|c|c|c|c|c|c|c|}
\hline & \multicolumn{2}{|c|}{ Dependent Variable ------> } & \multicolumn{6}{|c|}{ Turnout in 2007 Round of Elections } \\
\hline & & & \multicolumn{4}{|c|}{ Probit } & \multicolumn{2}{|c|}{ IVProbit } \\
\hline & & & & ME & & ME & & ME \\
\hline \multirow{10}{*}{$\begin{array}{c}\text { Main Explanatory } \\
\text { Variables }\end{array}$} & \multirow{2}{*}{ time } & coef & 0.44 & \multirow{2}{*}{0.14} & 0.31 & \multirow{2}{*}{0.09} & & \\
\hline & & std err & $0.14 * * *$ & & $0.13 * *$ & & & \\
\hline & \multirow{2}{*}{ treat } & coef & -0.16 & \multirow{2}{*}{-0.05} & -0.21 & \multirow{2}{*}{-0.06} & & \\
\hline & & std err & 0.13 & & 0.14 & & & \\
\hline & \multirow{2}{*}{ time*treat } & coef & 0.11 & \multirow{2}{*}{0.04} & $\mathbf{0 . 3 3}$ & \multirow{2}{*}{0.09} & & \\
\hline & & std err & 0.19 & & $0.20 *$ & & & \\
\hline & \multirow{2}{*}{ secure (inst. treat) } & coef & & & & & 0.37 & \multirow{2}{*}{0.1} \\
\hline & & std err & & & & & $0.22 *$ & \\
\hline & \multirow{2}{*}{ Constant } & coef & 0.3 & & -0.46 & & & \\
\hline & & std err & $0.15^{* *}$ & & 0.28 & & & \\
\hline \multicolumn{3}{|c|}{ Regional Fixed Effects/Dummies } & \multicolumn{2}{|c|}{ Yes } & \multicolumn{2}{|c|}{ Yes } & \multicolumn{2}{|c|}{ Yes } \\
\hline \multicolumn{3}{|c|}{ Demographic/Political Controls } & \multicolumn{2}{|c|}{ No } & \multicolumn{2}{|c|}{ Yes } & \multicolumn{2}{|c|}{ Yes } \\
\hline \multicolumn{3}{|c|}{ Number of Observations } & \multicolumn{2}{|c|}{2321} & \multicolumn{2}{|c|}{1927} & \multicolumn{2}{|c|}{977} \\
\hline \multicolumn{3}{|c|}{ Pseudo R2 (P) Chi2 (IV-P) } & \multicolumn{2}{|c|}{0.05} & \multicolumn{2}{|c|}{0.09} & \multicolumn{2}{|c|}{198.76} \\
\hline
\end{tabular}

Note: Standard errors reported; these are corrected by clustering at the location (census area) level.

* significant at $10 \%$;* significant at $5 \%$; *** significant at $1 \%$. 


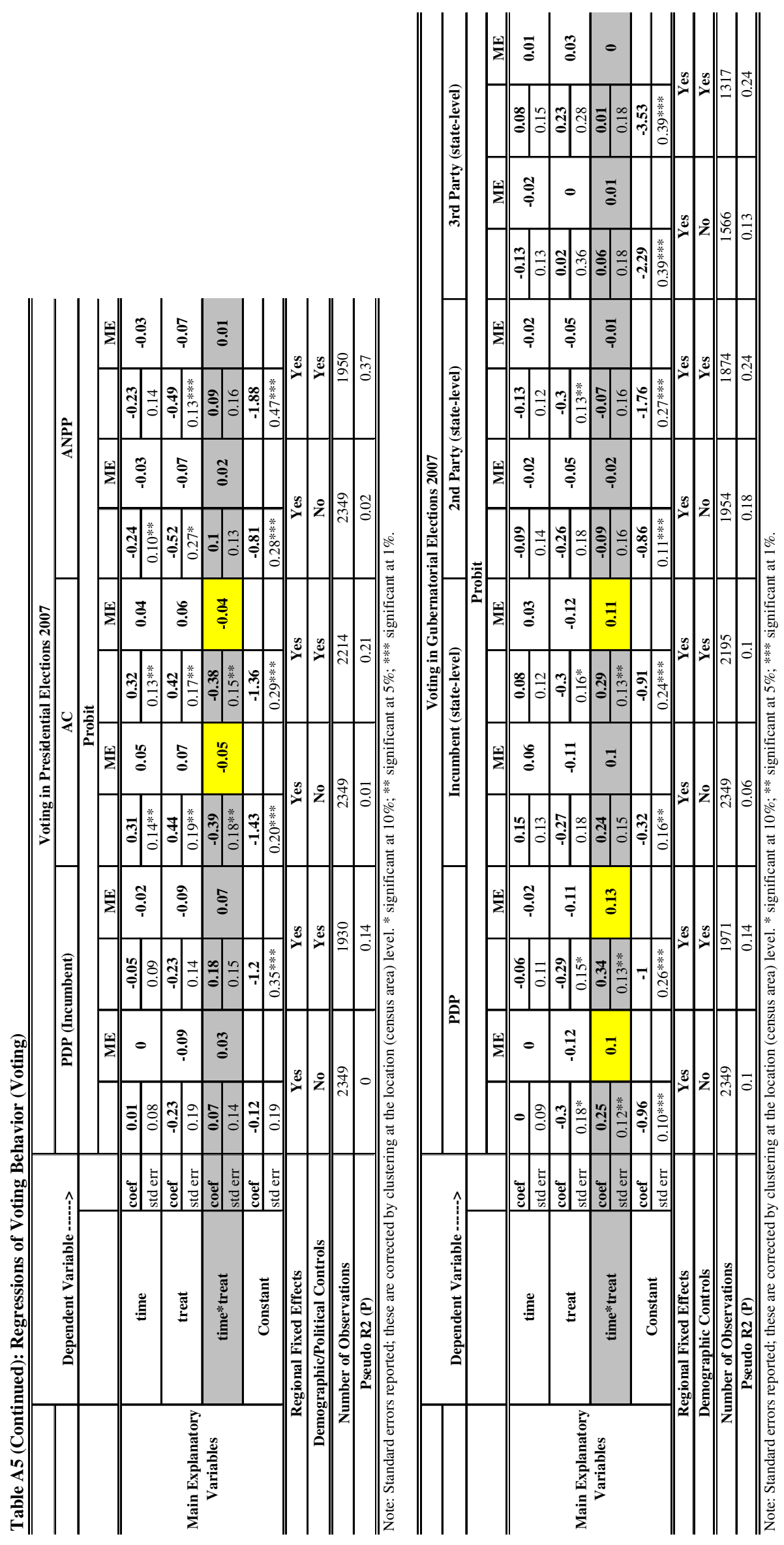




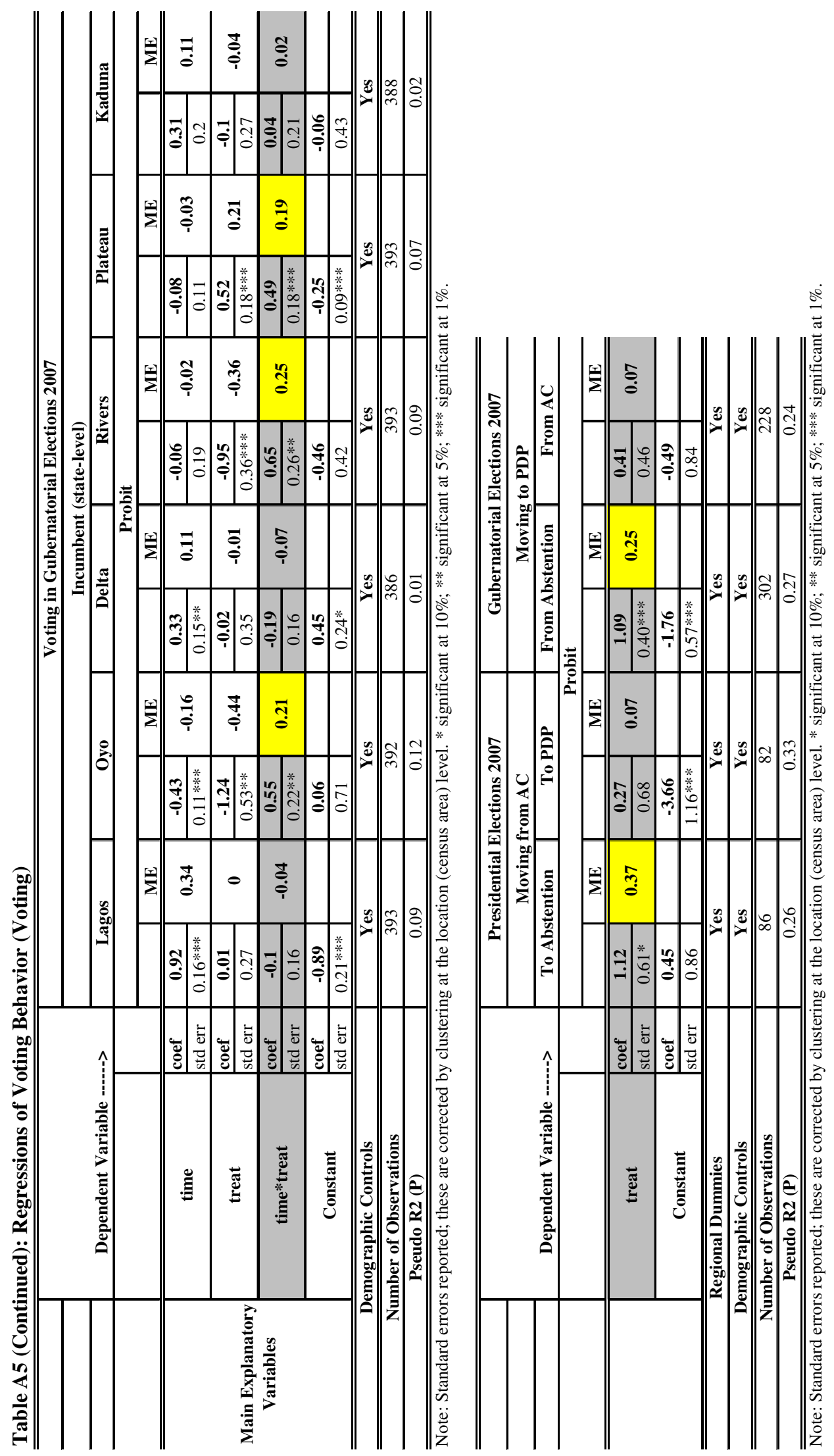




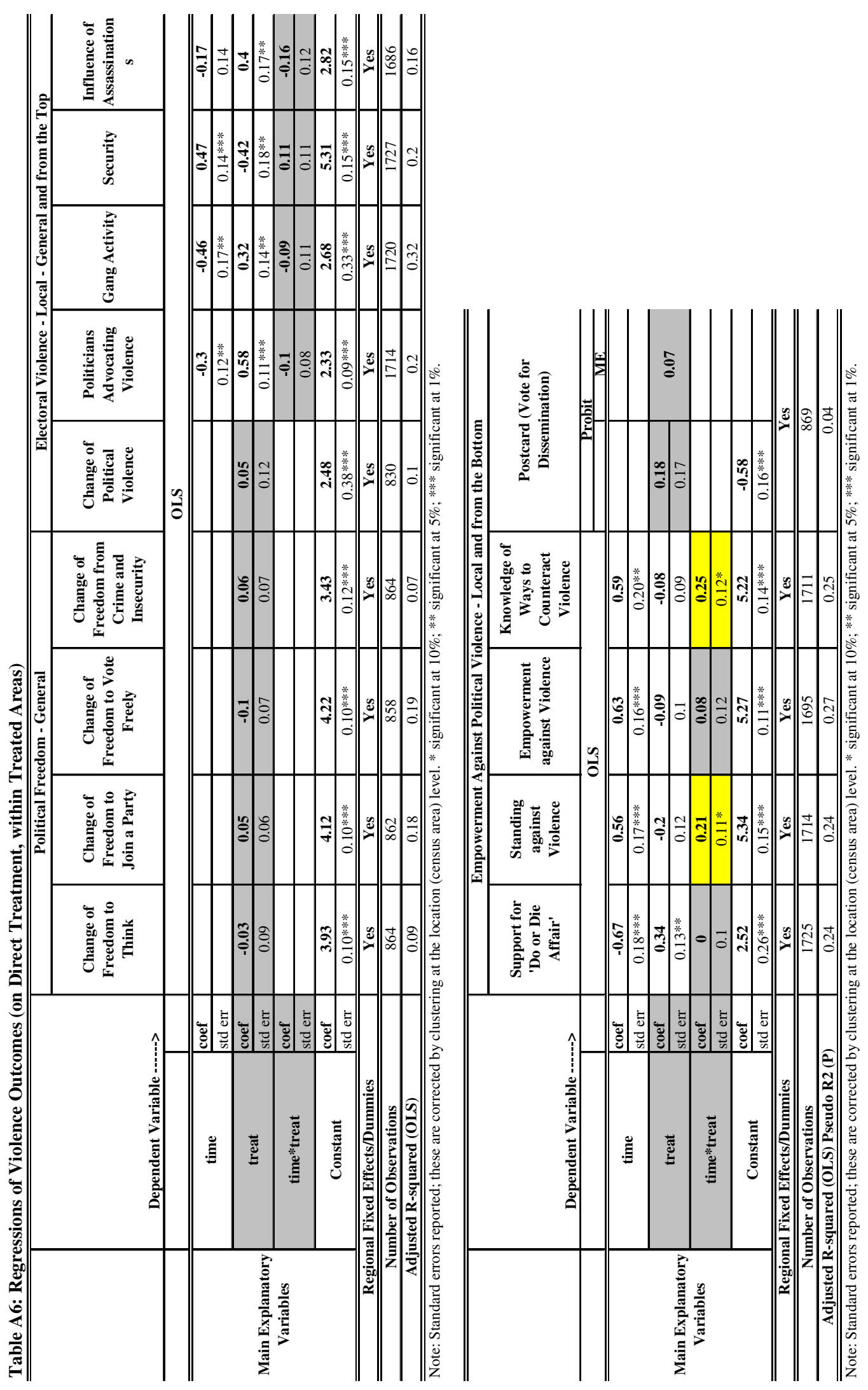


Table A6 (Continued): Regressions of Violence Outcomes (on Direct Treatment, within Treated Areas)

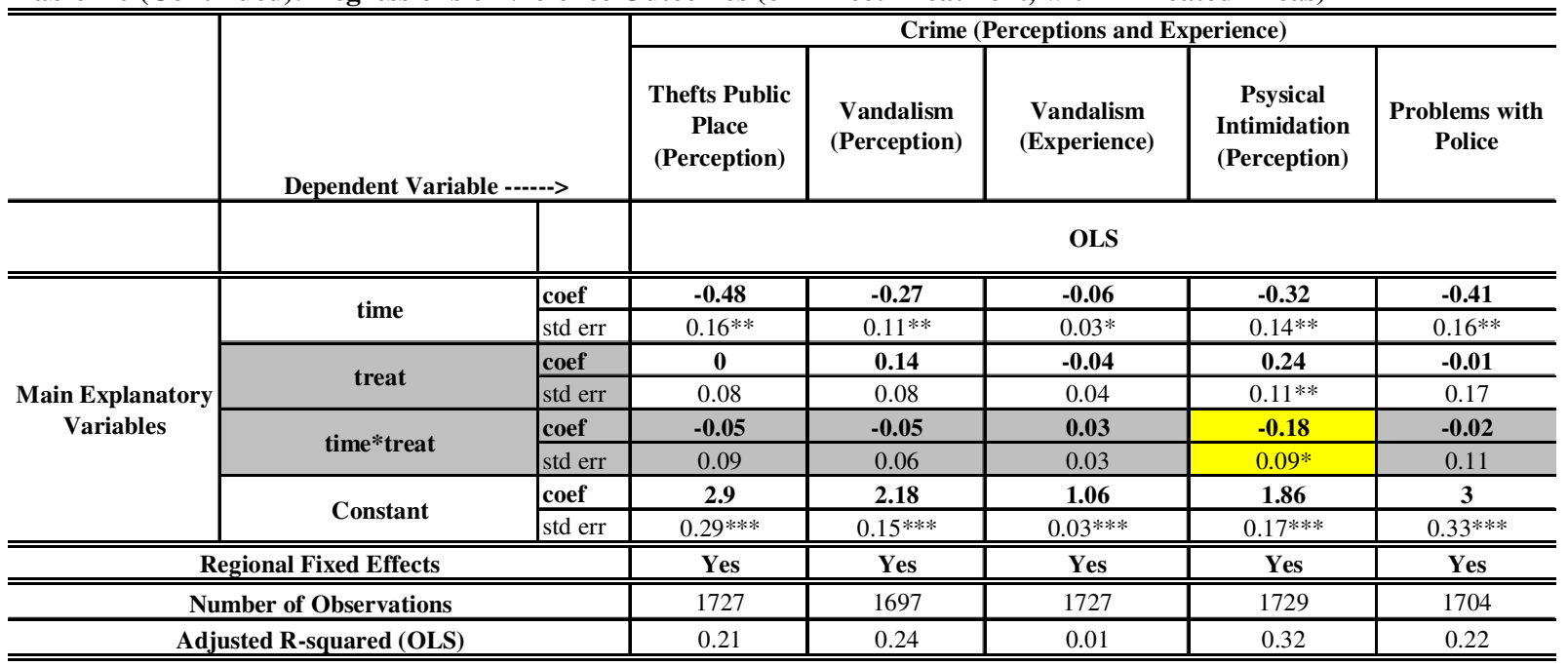

Note: Standard errors reported; these are corrected by clustering at the location (census area) level.

* significant at $10 \%$; ** significant at $5 \%$; *** significant at $1 \%$ 


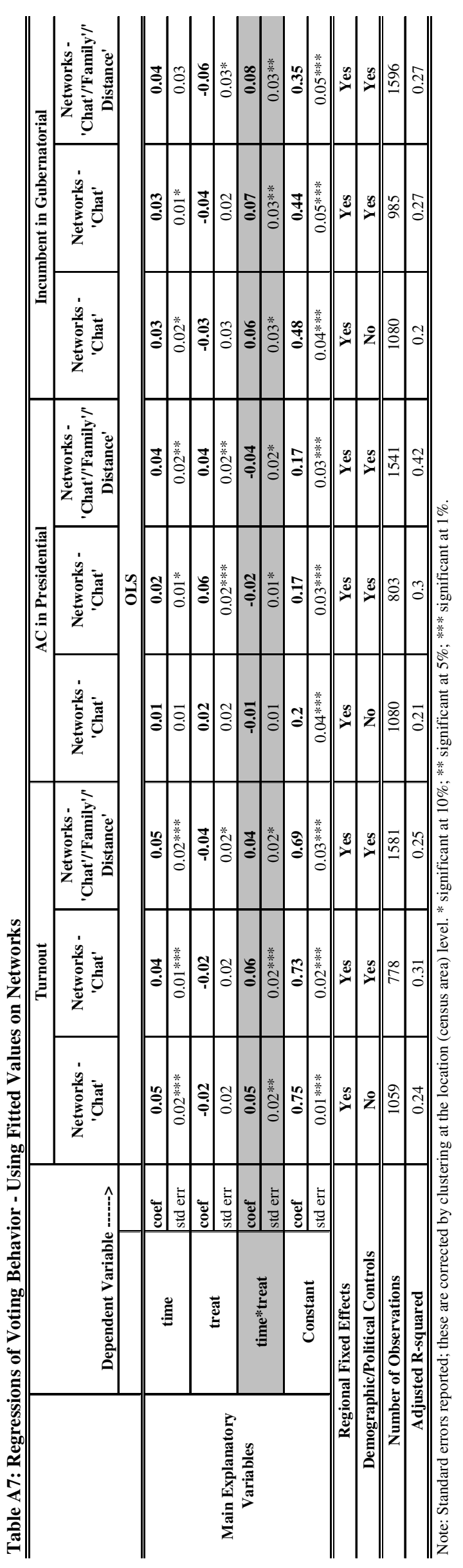




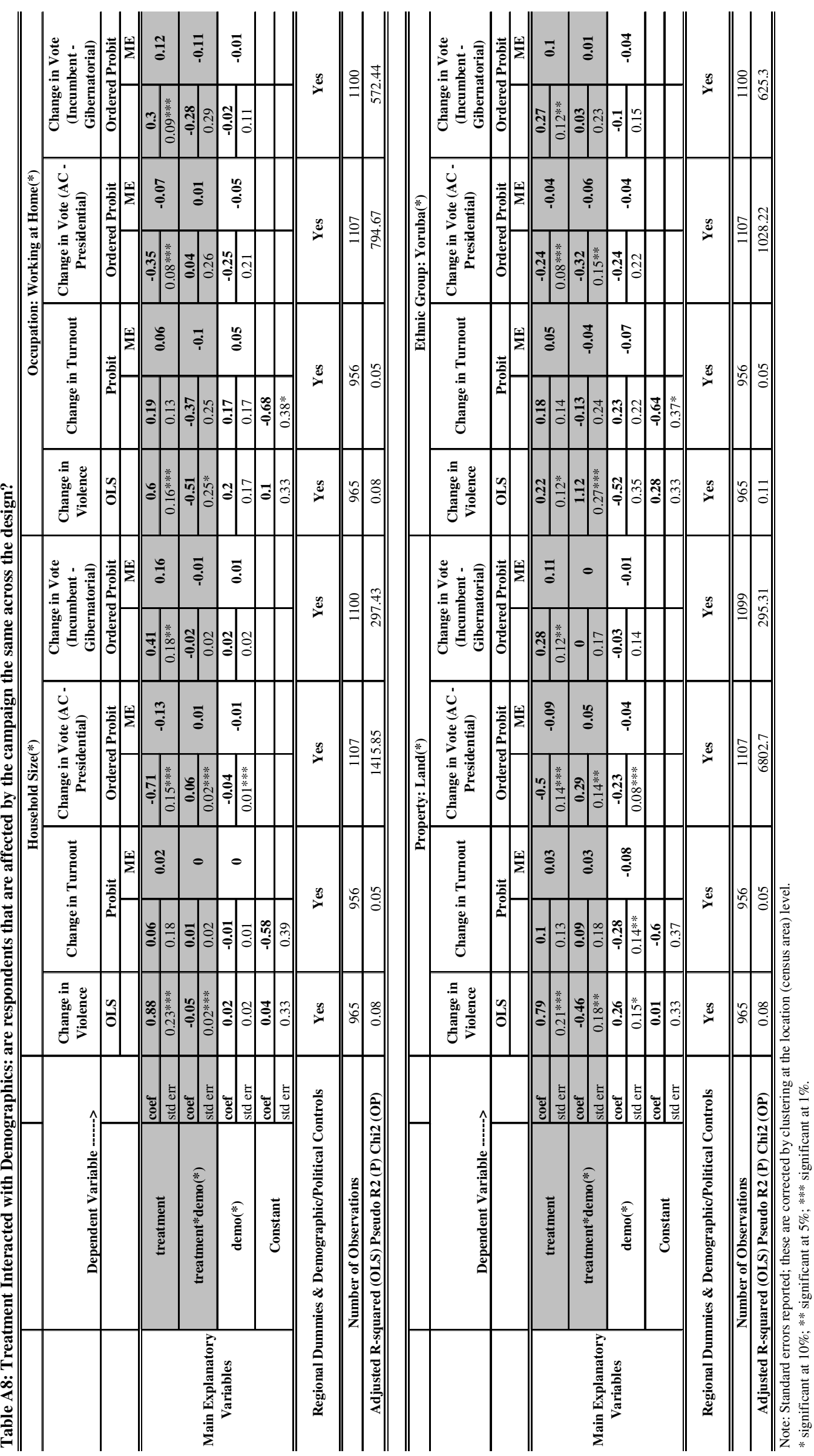




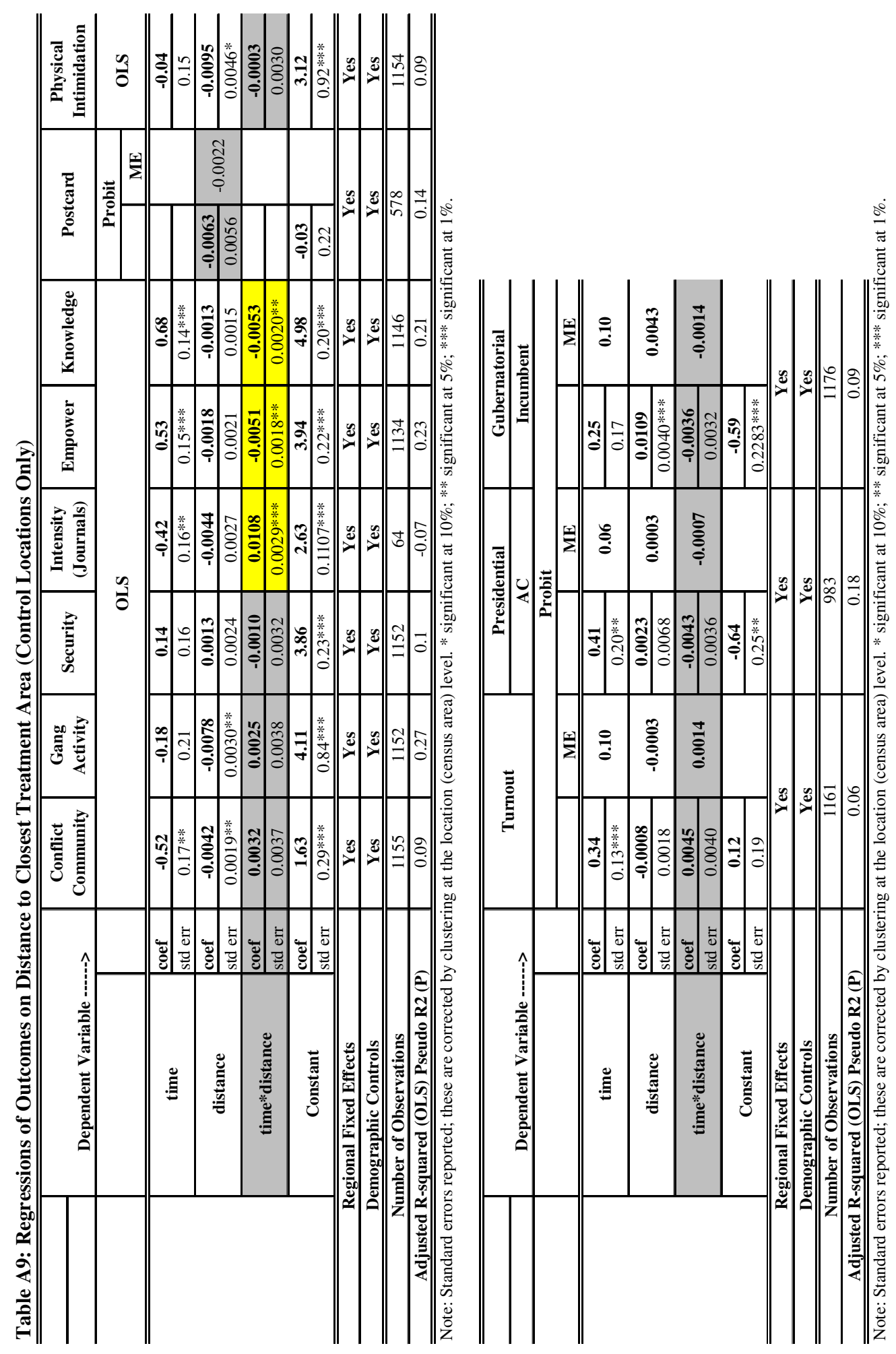

